\title{
Linking the infilling of the North Branch in the Changjiang (Yangtze) estuary to anthropogenic activities from 1958 to 2013
}

\author{
Zhijun Dai ${ }^{1,2}$, Sergio Fagherazzi ${ }^{2}$, Xuefei Mei $^{1}$, Jiyu Chen $^{1}$, Yi Meng ${ }^{1}$ \\ ${ }^{1}$ State Key Lab of Estuarine \& Coastal Research, East China Normal University, Shanghai, China \\ ${ }^{2}$ Department of Earth and Environment, Boston University, USA \\ Corresponding author \\ Zhijun Dai \\ State Key Lab of Estuarine and Coastal Research, \\ East China Normal University, \\ Shanghai, \\ China \\ Email: zjdai@ sklec.ecnu.edu.cn; \\ Tel: +862162233458; \\ Fax: +862162546441
}

Running title: Infilling of the North Branch of the Changjiang estuary

\begin{abstract}
Many tidally-dominated estuaries of the world are experiencing variations in bottom topography due to changes in natural forcings and intensive human activities. Here we focus on the morphological evolution of the North Branch (NB), a tidallydominated distributary of the Changjiang estuary. Our analysis is based on long-term bathymetric and hydrological data collected between 1950 and 2010. The results show that mean water depth, channel volume below $0 \mathrm{~m}$, and channel volume below $-5 \mathrm{~m}$ have respectively decreased by $43 \%, 53 \%$ and $92 \%$ in the last 50 years. A reduction of the whole estuarine surface with aggradation in elongated tidal sand bars and erosion at the mouth are the main morphological variations of the NB, while a decrease in channel volume below $-5 \mathrm{~m}$ due to infilling is the second mode of morphological change. While the drastic decrease in sediment load from upstream is likely unrelated to the silting of the NB, local land reclamation along the banks is directly responsible for the reduction of estuarine surface area and related tidal prism. Between 1958 and 2013, enhanced flood-tide currents resulted in a large import of sediments from offshore into the $\mathrm{NB}$, triggering a sustained decrease in channel volume below $0 \mathrm{~m}$. It is argued that the recovery of the funnel-shaped configuration of the estuary by restoring mud flats over $0 \mathrm{~m}$, dredging the southern part of the estuary bend and forbidding land reclamation could prevent the silting of the NB, otherwise the NB will likely vanish in few decades.
\end{abstract}

Keywords: Estuary; Delta morphodynamics; Tides; Anthropogenic activities. 


\section{Introduction}

Estuaries are interfaces between fluvial upland systems and wave- or tide-dominated regimes of the open coast, resulting in complex sediment- and morpho-dynamics (van der Wal et al., 2002). Because of their location and ubiquity, estuaries play a vital role in the fluxes of water and nutrients between lands and oceans, thus providing economically and ecologically indispensable goods and services to communities (USEPA, 1993; Capo et al., 2006). Most estuaries of the world are facing severe challenges due to anthropogenic activities, such as dam construction, sand excavation, and land reclamation (van der Wal et al., 2002; Kim et al., 2006; Anthony et al., 2015). Many estuaries formed when sea level rose more than $100 \mathrm{~m}$ from the last glacial lowstand to its present level about 6000 years ago (Wolanski, 2006; Perillo, 1995; Heap et al., 2004). In spite of their millennial life-span (Roy et al., 2001), several estuaries worldwide have experienced drastic morphological changes, and few still preserve the original broad intertidal area due to land reclamation carried out in the last century (Woodroffe, 2003; Wolanski, 2006). Reduction in intertidal area and related tidal prism has often resulted in the infilling of the estuary, leading to navigation problems and habitat modification (van der Wal et al., 2002; van der Wegen et al., 2010; Morris, 2013; Canestrelli et al., 2014).

Bathymetric variations in estuaries are determined by wave climate, the availability of riverine and coastal sediments, and fluvial and tidal hydrodynamics (Wright and Coleman, 1973). Some studies further indicate that sediment dynamics in many tidallydominated estuaries are controlled by the asymmetry between flood and ebb (Postma, 1961; Aldridge, 1997), gravitational circulation (Uncles and Stephens, 1997), and tidal pumping (Wolanski and Spagnol, 2000; Mitchell et al., 2003). In recent decades anthropogenic activities have had a dramatic effect on the morphology of estuaries, modifying the hydrodynamics and the extension of intertidal flats (van der Wal and Pye, 2004; Kim et al., 2006; Liu et al., 2007; Cuvilliez et al., 2009). Cuvilliez et al. (2009) indicate that the tidal prism within the Seine estuary had reduced by more than $31 \%$ from 1978 to 2005 due to sand accumulation in the channel. Kim et al. (2006) showed that the macro-tidal Keum river estuary in the eastern Yellow Sea has undergone siltation and morphological change since 1994 because of extensive coastal development. Spearman et al. (1998) indicate that considerable siltation with a net loss in tidal volume of around 50\% was measured in the muddy estuary of the River Lune, UK, because of the construction of seawalls and dredging activities. A similar outcome was observed in the Mersey estuary after the construction of a seawall, with significant bottom accretion between 1906 and 1977 (Thomas et al., 2002).

More estuaries could become unstable and respond much faster to human disturbances in the future (Wolanski, 2006). To better address these dynamics, 
laboratory experiments (Tambroni et al., 2005), numerical models (Lanzoni and Seminara, 2002; Todeschini et al., 2008; de Swart and Zimmerman, 2009; Pittaluga et al., 2014; Canestrelli et al., 2010; 2014), analytical methods (Seminara et al., 2010), and hydrological and morphological investigations (van der Wal et al., 2002; Kim et al., 2006) have tried to address morphological equilibrium in tidally-dominated estuaries, where upstream water and sediment discharges are negligible. Because of the combination of complex hydrological conditions and increasing human manipulations of these systems in recent decades, more studies are required to understand the coupling between estuarine sediment budget and morphological change. It is vital to discern causes of estuarine siltation and predict the long-term morphological evolution of estuaries, especially in the Changjiang Estuary, the largest estuary in China.

The Changjiang (Yangtze) River is the longest river in Asia and the third-longest in the world with a length of around $6300 \mathrm{~km}$, having a mean water discharge of $905 \times$ $10^{9} \mathrm{~m}^{3} / \mathrm{yr}$ and a mean sediment discharge of $0.43 \times 10^{9}$ ton $/ \mathrm{yr}$ in the period 1950-2000 (BCRS, 2010). In the lower reaches of the Changjiang, the river channel bifurcates at four islands, Chongming, Hengsha, Changxing and Jiuduan Shoal (Fig. 1a), forming a 3-tiered branching delta that has 4 distributary mouths debouching in the East China Sea (North Branch, North Channel, North Passage, and South Passage, Fig. 1b). The mean tidal range in the Changjiang estuary is about $2.67 \mathrm{~m}$ and the peak tidal velocity is $1 \mathrm{~m} / \mathrm{s}$. Since the Three Gorges Dam (TGD), the world's largest river engineering project, started operating in 2003, the sediment load from upstream into the delta has reduced by $70 \%$ (Dai et al., 2014). The Changjiang delta has suffered from morphological change driven by the drastic decrease in sediment load from upstream. Yang et al. (2007) showed that the decrease in sediment load has led to the conversion from progradation to erosion of the delta front. Wang et al. (2013) showed that the Changjiang delta has experienced overall erosion since 1980. However, Dai et al. (2013) indicate that deposition in the peripheral groin fields along the shipping channel within the North Passage and deepening of the shipping channel itself were due to local channel maintenance, rather than large-scale morphodynamic change (Fig. 1b). More recently, Dai et al. (2015) studied sediment dynamics in the South Passage showing that significant accretion is present despite the decline of upstream sediment input.

While there is an on-going international debate about the sensitivity of the Changiiang estuary to a decrease in upstream sediment load (Yang et al., 2007; Syvitski et al., 2009; Wang et al., 2013; Chen et al., 2010), little information is available on the morphological change and possible infilling of the macro-tidal North Branch (NB), the northernmost distributary of the delta (Fig. 1c). The main goals of this study are to: (1) explore the spatial and temporal variability in bottom elevation of the NB in the period 1958-2013; (2) discern patterns of morphological evolution of the NB; (3) diagnose whether the morphological evolution of the NB is due to a decrease in upstream sediment load or to local anthropogenic disturbances. Our overarching goal is to 
evaluate the possible impacts of the distal TGD on the whole Changjiang delta. The results presented herein could also provide important information for other tidallydominated deltas or estuaries with limited fluvial discharge.

\section{Physical setting of the North Branch}

The planar configuration of the NB is funnel-shaped, leading to the deformation of the semi-diurnal tidal wave during its propagation inland (Fig. 1c) (Chen et al., 2003). The maximum tidal range of the NB mouth is about 4 6 m (Feng et al., 2009), therefore the estuary is tidally-dominated according to Davis's classification (Davis, 1964). The mean spring tidal ranges at Lianxing, Santiao, and Qinglong are 3.77, 3.82, and $3.81 \mathrm{~m}$, respectively (Zhou et al., 2005; Feng et al., 2009) (Fig. 1c). The mean and maximum tidal flow velocity at Qinglong are $1.25 \mathrm{~m} / \mathrm{s}$ and $3.12 \mathrm{~m} / \mathrm{s}$ (Chen et al., 2003).

The surficial deposits within the NB are mainly sand and silt (Zhou et al., 2005). Significant intertidal mud is accumulated on the higher tidal flats. Elongated, fingershaped tidal sand bars are distributed over the estuary bottom along the flow direction (Zhou et al., 2007) (Fig. 1c). based on its topographic and hydrodynamic characteristics, the NB is usually divided into three segments as follows: the upper reach between Chongtou and Qinglong that is controlled by the weakening of tidal flows, the middle reach between Qinglong and Touing that is characterized by frequent sediment accretion and erosion periods due to strong tidal flows, and the lower reach between Touxing and Lianxing that is defined by shoal-channel patterns due to the effect of flood/ebb tidal currents (Chen et al., 1982; Dai et al., 2011) (Fig. 1c).

\section{Materials and methods}

\subsection{Materials}

Bathymetric surveys at different time scales are invaluable for developing insight into the morphodynamics of an estuarine system (van der Wegen et al., 2010). In the last two decades, many studies have been carried out to understand morphological change and deposition patterns within estuaries based on bathymetry-derived DEMs (Thomas et al., 2002; Fagherazzi et al., 2006; Jaffe et al., 2007; Dai et al., 2014). In order to study the NB evolution, bathymetric information from different charts spanning the period 1958-2013 was acquired and digitized with ArcGis 10 (Table 1). The bathymetry was measured between early May and early June, prior to peak discharge, and was completed before August, using a DESO-17 echo-sounder or a single-frequency sounding instrument. The vertical error of the measurements is about $0.1 \mathrm{~m}$, and a Trimble GPS was used to retrieve the positioning with an error within $1 \mathrm{~m}$ (Dai et al., 2014). The depth values in different years were first converted to elevation relative to the Beijing-1954 Datum; the Kriging scheme was then used to interpolate the digitized data into a grid with resolution of $250 \mathrm{~m} \times 250 \mathrm{~m}$. Six synchronous tidal flow surveys were carried out at Qinglong (BZ1) and Santiao (BZ2) during spring tide, on 1 Sept. 
1984, 3 Sept. 2001, 1 March 2002, 4 March, 2007, and 5 March 2011 (Fig. 1c). In addition, a large-scale synchronous tidal flow survey, spanning 11 gauging stations in the NB and South Branch of the Changjiang estuary, was conducted during spring tide in 22, Sept. 2002. Tidal ranges at all stations were converted to elevation relative to Beijing-1954 Datum. Tidal velocity was recorded with a Sea bird velocity meter and an Acoustic Doppler current Profile.

Measurements of ebb tidal currents in the NB between 1958 and 2011 were obtained from the Hydrological Bureau of the Changjiang estuary. Yearly runoff and sediment load were collected at Datong, the tidal limit of the Changjiang estuary, by the Bulletin of China River Sediment for the period 1953-2013.

\subsection{Methods}

Based on the digitized charts, the channel volume below $0 \mathrm{~m}$, below $-5 \mathrm{~m}$, and the mean water depth were extracted with ArcToolBox 10 for different years. In order to detect the longitudinal bottom variability of the river, the bottom profile at the channel center was extracted from the DEM in selected years. The NB had experienced significant morphological variations during the period 1958-2013, with a large region turning to land (Yun, 2004). To compare erosion and deposition patterns in different years, here we focus on the area, common to all DEMs, that was never reclaimed. Erosion or accretion rates were directly obtained from the DEMs of this area, for different time interval.

The coefficient of flow dominance is calculated by dividing the peak tidal discharge during ebb by the sum of the peak tidal discharges in ebb and flood. This coefficient represents the relative strength of the ebb tidal current (Simmons, 1955). When the coefficient of flow dominance is over $50 \%$, the flow is ebb-dominated, otherwise it is flood-dominated. Here, data from six cruises were used to obtain the coefficient of flow dominance in different years.

In order to determine possible deposition patterns in each time period, elevation differences between DEMs were analyzed with Empirical Orthogonal/Eigen Function (EOF). EOF is a classical multivariate statistical technique, which has been widely applied to estuarine morphodynamics and sediment dynamics analyses (Emery and Thomson, 2001; Liu and Lin, 2004; Lane, 2004; Dai et al., 2013, 2015). The advantages of the EOF are that complex original data can be described by a relatively small set of uncorrelated variables via linear transformations, with the new variables being mutually orthogonal (Dai et al., 2008). The bathymetric variability of the NB between 1958 and 2013 can thus be quantified by a set of eigenvalues; each eigenvalue and its EOF mode define the relative importance of the eigenfunction, which is a distinct mode of morphological change. Negative values reflect sediment erosion and an increase in channel volume, while positive values represent deposition and a decrease in channel volume (Emery and Thomson, 2001; Dai et al., 2015). Moreover, the more correlated 
the data are, the more covariance can be accounted for the first few EOF modes (Liu and Lin, 2004; Emery and Thomson, 2001). The remnant eigenfunctions are usually neglected due to the effect of noise contained in the dataset (Wallace and Dickinson, 1972).

\section{Results}

\subsection{Bathymetric change along the North Branch}

Since variations in bathymetric DEMs can precisely represent morphological dynamics (van der Wegen et al., 2010), here we show distributions of NB water depth in different years (Fig. 2). The NB water depth ranges from $8 \mathrm{~m}$ to $0 \mathrm{~m}$ with the most frequent depths between $5 \mathrm{~m}$ and $2 \mathrm{~m}$. The NB is therefore much shallower than the three other distributaries of the Changjiang estuary, the depth of which is around $8 \mathrm{~m}$ (Dai et al., 2013, 2015). Water depths less than $2 \mathrm{~m}$ are mainly present around the entrance of the NB, along the upper segment, and on the lateral tidal flats of the middle segment. On the contrary, areas with water depth above $5 \mathrm{~m}$ are present in the lower segment, even though occasional events can deepen the upper and middle segments as well (Fig. 2). Between 2003 and 2013, water depths experienced oscillations (Fig. 2), with large water depths in 2007, 2009, 2013, and low water depths in 2005, 2008, 2010 (Fig. 2).

The mean water depth along the NB is $3.86 \mathrm{~m}$ for the period 1958-2013, but it has greatly changed in recent decades, even though there are some fluctuations between 2003 and 2010 (Fig. 3a). The mean water depth decreased by $47 \%$ from $5.85 \mathrm{~m}$ in 1958 to $3.14 \mathrm{~m}$ in 2003 (Fig. 3a). Statistically significant downward trends have been detected in the mean water depth from 1958 to 2013 (Fig. 3a).

Moreover, the longitudinal profile of the estuary indicates the presence of several tidal bars that evolve in time. Two bars accrete in time in the middle and lower segments, while the number of tidal bars gradually decreases in the upper segment. The profile elevations are mainly below $0 \mathrm{~m}$ in the period 1958-2003, and turn to above $0 \mathrm{~m}$ in the period 2005-2013, especially in the part of the estuary middle segment farthest from the mouth (Figure 4). This reveals that the whole NB estuary could be likely infilled due to sustained siltation.

\subsection{Changes in siltation along the North Branch}

The estuary volume below $0 \mathrm{~m}$ has dropped by $53 \%$ from $1.17 \times 10^{9} \mathrm{~m}^{3}$ in 1958 to $0.54 \times 10^{9} \mathrm{~m}^{3}$ in 2013, in accordance with the trend of mean water depth (Fig. 3b). In other words, the mean yearly decrease in channel volume below $0 \mathrm{~m}$ is equal to 11.4 $\times 10^{6} \mathrm{~m}^{3} / \mathrm{yr}$. The volume below $-5 \mathrm{~m}$ has decreased of about $92 \%$ from $302 \times 10^{6} \mathrm{~m}^{3}$ in 1958 to $26 \times 10^{6} \mathrm{~m}^{3}$ in 2013 (Fig. 3c). Both variations in estuarine volume are statistically significant with a $p$ level of 0.001 (Fig. 3b, 3c). This information is also 
reflected in the estuarine bottom profile, with the channel thread becoming shallower and flatter (Fig.1c, Fig. 4).

Between 1958 and 2013, the mean deposition rate is around $90 \times 10^{6} \mathrm{~m}^{3} / \mathrm{yr}$ (Fig. 5). However, limited deposition was present between 1958 and 2003 with a rate of 6.45 $\times 10^{6} \mathrm{~m}^{3} / \mathrm{yr}$, while high deposition rates can be found from 2004 to 2013 with net yearly accretion of $209 \times 10^{6} \mathrm{~m}^{3} / \mathrm{yr}$ (Fig. 5). These results indicate that the NB is silting leading to a reduction in channel volume. The mean deposition rate presents fluctuations, especially in the lower segment near the mouth (Fig. 5). The channel bottom switched from erosion to accretion in 2003, presenting relatively small oscillations before 2003 (Fig. 5a-5r). It is found that in the period 2004-2013, accretion occurred in bursts, such as in the period 2007-2008, followed by intense erosion, such as in the period 2008-2009 (Fig. 5h-5g, 5r). However,, the amount of net yearly deposition is much larger than that of net erosion (Fig. 5r). Furthermore, during the period 1958-2003, the accretion zone was mainly concentrated in the middle and upper segments, with a total deposition exceeding $1 \mathrm{~m}$; while the eroded area was mainly located in the lower segment, which eroded of about 1-2 m (Fig. 5a-q).

\subsection{Patterns of morphological change obtained by EOF}

Erosion and deposition patterns were highly variable in our study period. Here we quantify the major modes of morphological change using the EOF technique. The same technique was already used in both the South and North Passages of the Changjiang estuary (Dai et al., 2013, 2015). The EOF analysis shows that variations in bathymetric data between 1958 and 2013 are highly correlated with the first two eigenmodes, which explain over $78 \%$ of the standardized covariance (Fig. 6). Therefore, the first two modes represent the main patterns of morphological variation in the $\mathrm{NB}$, while the remaining modes account for less than $10 \%$ of the covariance and can be considered as noise and thus neglected (Emery and Thomson, 2001).

The first mode accounts for $62.5 \%$ (Fig. 6a). The contour plot of the eigenvector indicates accretion in the upper reach, in the central part of the middle reach, and in an elongated bar in the lower reach. The basic deposition areas coincide with the elongated bars in the upper and middle reaches, as well as the Huanggua shoal, which is located in the lower reach of the NB (Fig. 6a). The eroding areas are mainly found at the estuary mouth, and within the flood channels of the NB (Fig. 1c, Fig. 6a). The corresponding temporal pattern of the eigenvalues shows that all coefficients are positive in time with some periodic fluctuations and a decreasing trend at a significant level of 0.1 (Fig. 6b). Therefore, considering the product of eigenvectors and corresponding eigenvalues, the aggradation areas will continue accreting while the eroded area will deepen. It is noted that there is a statistical significant relationship between the eigenvalues and the channel volume below $0 \mathrm{~m}(\mathrm{r}=0.72, \mathrm{p}<0.05)$ (Fig. 7a). Therefore the first eigenmode represents the reduction in river depth over the period 1958-2013, with aggradation of 
the tidal sand bars, deepening of the flood channel, and scour at the estuary mouth.

The second eigenmode contributes to $15.8 \%$ of the covariance. The eigenvector is negative across most of the NB (Fig. 6c) with positive values mainly concentrated near the mouth at a depth of 5m, where the first eigenvector displays deposition (Fig. 6a, 6c). Negative values in this mode are less than those of the first mode (Fig. 6a, 6c). The temporal characteristics of this mode are represented by the eigenvalues curve that shows a secular decline at a significant level of 0.1 (Fig. 6d). In comparison with those of the first mode, the eigenvalues of the second mode display large variations, ranging from -0.49 to 0.25 . Moreover, the slope of the decreasing trend is larger (Fig. 6d). This suggests that this mode of morphological change is responsible for a larger portion of the decrease in estuarine volume. Moreover, a decreasing trend is also detected for the channel volume below $-5 \mathrm{~m}$, and a strong correlation is found between the decrease in channel volume below -5 m (Fig. 3c) and the temporal eigenvalue (Fig. 7b). Taken together, these results indicate that this mode is probably representative of variations of the river channel volume below $-5 \mathrm{~m}$, accounting for its frequent oscillations.

\section{Discussion}

\subsection{Possible relationship between bathymetrical change in the NB and variations in water discharge and sediment load of the Changjiang River}

Some studies indicate that variations in water and sediment discharge from the Changiiang river has had a strong impact on the entire delta (Yang et al., 2007; Syvitski et al., 2005, 2009; Chen et al., 2010; Dai et al., 2014). Water discharge at Datong during the period 1953-2013 experienced minor fluctuations, and it has not shown significant variations in the last decade, since the beginning of the TGD operations in 2003 (Fig. $8 \mathrm{a}, 8 \mathrm{~b})$. On the contrary, there is a statistical significant reduction in sediment load into the delta $(r=0.83, p<0.001)$ (Fig. 8c). The mean yearly sediment load at Datong decreased from $425 \times 10^{6}$ ton/yr in the period $1953-2003$ to $145 \times 10^{6}$ ton/yr in the period 2003-2013. This means that the sediment input into the estuary declined by about $70 \%$ since 2003, due to the construction of the TGD (Fig. 8c, 8d).

The combination of a stable yearly water discharge and a drastic decrease in sediment load seems to be unrelated with the silting of the NB; in fact a decrease in sediment load into the estuary should lead to shoreline erosion and bottom deepening (Syvitski et al., 2005, 2009). Data show that erosion/accretion patterns in the Changjiang estuary are likely controlled by the partition of the discharge and sediment load into the distributaries (Dai et al., 2014). Water fluxes in the NB decreased drastically from $12 \%$ of the total river flow to the ocean in 1958 to $-5 \%$ in 1959 , with the negative value meaning a net flux from the ocean to the river through this distributary, with the water eventually returned to the ocean from the South Branch. This is supported by the high flood-tide velocity in the NB in comparison with the ebb dominated South Branch (Fig. 9). At the bifurcation between NB and South Branch, values of the flood current 
velocity in the NB are much larger than those in the South Branch (Fig. 9). The NB discharge fluctuated around $-5 \%$ between 1959-1988, increased slightly to $1-5 \%$ between 1987 and 2001, and decreased to $-24 \%$ in 2011 (Fig. 10). As a result, a conspicuous volume of sediment was transported through the NB into the Changjiang during 1958-2013, as verified by previous studies (Yun, 2004; Dai et al., 2011). There is no significant difference in the ebb or flood discharge of the NB between flood season (Jul. and Aug.) and dry season (Feb. and Mar.), showing that water fluxes have small seasonal variations. Compared to the South Brach, the riverine flow in the NB is relatively small.

Occasional riverine flood events could be a significant factor affecting the NB morphological evolution. Several large floods such as those in 1989 and 1998 increased the yearly net flow from the Changjiang main stem to the NB (Fig. 8, Fig. 10). It is possible that riverine floods led to bottom erosion in the NB, as it is reflected by the high estuarine volume measured in 1990 and 2000 (Fig. 3a, 3b) as well as the related mouth erosion measured in the periods 1987-1990, 1990-1991, and 1997-1998 (Fig. 5).

\subsection{Control on river intake and blocking effect of the bend in the upper segment of the estuary}

Large flood events from the catchment can greatly change the channel volume of the NB by piercing the estuarine bend in the upper reach thus increasing the bend angle (Fig. 10). It is well known that river bends can reduce water velocity and induce sediment siltation on the inner bank. The reduction in flow velocity on the inner bank is a function of the bend angle (Ikeda et al., 1981). The angle of the bend just below the bifurcation leading to the NB estuary ranged from $127^{\circ}$ to $144^{\circ}$ in the study period, with a mean value of $134^{\circ}$ (Fig. 11). We measured a decrease in bend angle at a significant level of 0.001 during the study period (Fig. 11). Also, a statistically significant correlation between bend angle, mean water depth, and channel volume is shown in Fig. 12. We put forward the hypothesis that variations in bend angle, which controls the exchange of water and sediment load between the Changjiang River and the NB, could contribute to variations in channel volume. The bend in the upper segment is the narrowest point of the estuary, so a reduction of its width is likely to choke both the riverine and tidal flow in the estuary thus reducing the flushing effect during ebb.

\subsection{Impact of land reclamation}

Land reclamation is one of the important human activities that affect the morphology of estuaries (Lane, 2004; Jaffe et al., 2007; Dai et al., 2015). While tidal range in the NB has barely changed in the last 50 years (Yun, 2004), significant intertidal area was reclaimed from 1958 to 2013 (Fig. 13), causing the loss of expansive mudflats bordering the main channel. For instance, the mud flat area in the upper and middle 
segments was over $352 \mathrm{~km}^{2}$ in the period $1958-1978$, and then reduced to $167 \mathrm{~km}^{2}$ in the period 1978-2001, to finally reach $166 \mathrm{~km}^{2}$ in the period 2001-2013 (Fig. 13). Mudflats reclamation had a strong impact on the morphology, resulting in a narrow channel with vanishing lateral flats. As a result, the geometry of the NB has shifted from funneled-shaped in 1958 to a channel with constant width in 2013 (Fig. 13). The corresponding tidal prism exhibited a downward trend between 1980 and 2010: the total volume of water entering the NB at Santiao during the flood portion of a spring tide was $14.5 \times 10^{8} \mathrm{~m}^{3}$ in Sep. $1984,11.8 \times 10^{8} \mathrm{~m}^{3}$ in Sep. 2001 (Yun, 2004), and $2.1 \times 10^{8}$ $\mathrm{m}^{3}$ in March, 2011.

It can be seen from Fig. 13 that the width of the NB at the Xinglong shoal decreased by $72 \%$ from $5.6 \mathrm{~km}$ in 1978 to $1.6 \mathrm{~km}$ in 1992, with the narrowest river width less than $1.45 \mathrm{~km}$ in 2013 (Fig. 13). Moreover, in the river bend along the upper segment, the river width rapidly decreased from $7.95 \mathrm{~km}$ in 1958 to $4.23 \mathrm{~km}$ in $1978,1.6 \mathrm{~km}$ in 2001 , and $1.2 \mathrm{~km}$ in 2013 . The rate of river width reduction is of $122 \mathrm{~m} / \mathrm{yr}$ in the period 19582013 (Fig. 13). In 2013 there are almost no mud flats above $0 \mathrm{~m}$ (Fig. 13). Due to the reduced tidal prism, enhanced deposition occurred in the upper and middle segments (Fig. 5). This result agrees with the dominant mode of morphological change, with reduction in channel depth and deposition in the landward region (Fig. 6). The loss of tidal flats caused by frequent and intensive land reclamation is directly responsible for the reduction in NB channel volume.

\subsection{Impact of flood tidal currents}

The drastic reduction in river width in recent decades has led to clear variations in tidal currents. The flow dominance coefficient measured in the upper and middle segments displayed a decrease from 1984 to 2011 (Fig. 14). Data collected at the two gauge stations reveal that the NB channel is becoming increasingly flood-dominated in time, with the flow dominance coefficient decreasing from around $50 \%$ in 1984 to $26 \%$ in 2011 (Fig. 14). This trend is in agreement with theoretical results of Friedrichs and Aubrey (1988), which show that the presence of extensive mudflats favor ebb dominance, while in narrow estuaries friction promotes flood dominance. Land reclamation has therefore strengthened the currents during flood, enhancing the channel's ability to transport sediment landward (Fig. 12). Strong ebb currents have a flushing effect in estuaries, remobilizing large volumes of sediments and delivering them to the ocean. On the contrary, flood currents move sediments landward, thus reducing or hindering the overall sediment output to the ocean. Since there has been almost no sediment input into the NB from upstream, most sediment flux into the NB should be from the ocean, driven by intense flood currents. The influence of river discharge on erosional and depositional patterns along the NB is weaker than that of tidal flows. As a result, the landward sediment transport does not display variations between wet and dry seasons, since the tidal component does not change across the year. The continuous decrease in channel volume below $0 \mathrm{~m}$ should thus also be ascribed to tidal pumping effects, which are enhanced by an increase in flood tidal currents 
(Wolanski and Spagnol, 2000). Wolanski et al. (2001) show that river flow regulation by dams in the macrotidal West Arm of the Ord river estuary, Australia, has triggered rapid silting. This is because the dams have suppressed large river floods, favoring tidal pumping of sediments into the estuary. The reduction of river depth by silting has also increased the tidal asymmetry, further favoring tidal pumping. Similar processes might be at play in the NB, with reduced river floods unable to flush sediments to the sea and the silting of the estuary enhancing tidal pumping.

Recent modelling studies have indicated that sediments scoured at the seaward portion of a tidal estuary are flushed toward the middle and inner reaches, generating a sediment front moving landward (Lanzoni and Seminara, 2002; Pittaluga et al., 2014). When the front reaches the inner part of the estuary, it forms a very shallow area (Lanzoni and Seminara, 2002).The model results are in agreement with the results presented herein, showing erosion at the mouth and accretion at the middle and upper portion of the NB (Fig. 2, Fig. 5). The longitudinal bottom profile is concave with peak values at the bend location, where bottom elevations have gradually increased from 1958 to 2013 (Fig. 4). This geometric configuration is not only similar to other tidal estuaries (Speer et al., 1991; Ayles and Lapointe, 1996), but also consistent with the results of numerical models (Lanzoni and Seminara, 2002; Pittaluga et al., 2014). The shallowing of the distributary has triggered an increase of about 0.1-0.2 $\mathrm{m}$ for both the highest and lowest tidal levels in the last 50 years (Yun, 2004).

\subsection{Fate of the North Branch and consequences for preservation and restoration policies}

It is important to understand whether a given estuary is infilling, eroding, or attains a morphodynamic equilibrium, especially in tidally-dominated coastlines and deltas (Canestrelli et al., 2014). Recent studies have computed the siltation timescale with analytical (Lanzoni and Seminara, 2002) and numerical techniques (Canestrelli et al., 2014). The channel volume of the NB below $0 \mathrm{~m}$ has decreased from $1.17 \times 10^{9} \mathrm{~m}^{3}$ in 1958 to $0.54 \times 10^{9} \mathrm{~m}^{3}$ in 2013 (Fig. 3b). Assuming that the average siltation rate of 11.4 $\times 10^{6} \mathrm{~m}^{3} / \mathrm{yr}$ calculated from Fig. $3 \mathrm{~b}$ continues, the timescale for channel infilling would be $\sim 50$ years. In other words, the NB will vanish in the 2060 s, which is comparable to the 36 years life span calculated by Yun (2004).

As one of the four distributaries of the Changijiang delta, the NB is an important intertidal ecosystem in China (Chen, 2007). It is argued that the lifespan of the NB could be likely delayed if large-scale restoration projects are implemented. First, the mudflats along the NB from the mouth to the upstream bent should be gradually restored in order to recover the original funnel shape and increase the tidal prism. Second, it is vital to favor water and sediment transport in the bend area of the upper segment, enlarging the bend angle by dredging and cutting the inner (southern) part of the bend. In fact, water and sediment fluxes in the bend area are hindered due to shallow depths, favoring sediment siltation. In addition, land reclamation along the NB should be banned. 


\section{Conclusions}

The long-term morphodynamic evolution of tidally-dominated estuaries has received wide attention in the recent past, since these estuaries could drastically change their morphology due to sea level rise, enhanced sediment siltation/erosion driven by changes in sediment fluxes, and land reclamation. The North Branch, a tidallydominated distributary of the Changjiang delta, has displayed distinct morphological change in the last 50 years. Here we summarize the main observations and measurements of this morphological evolution:

(1) The mean water depth, the channel volume below $0 \mathrm{~m}$, and the volume capacity below $-5 \mathrm{~m}$ experienced a significant decrease from 1958 to 2013. The mean water depth along the NB has decreased by $43 \%$. The channel volume below 0 $\mathrm{m}$ and $-5 \mathrm{~m}$ has decreased by $53 \%$ and $92 \%$, respectively.

(2) Two basic morphological patterns have characterized the evolution of the NB in the last 50 years. The dominant pattern is a reduction of the entire channel volume, accompanied with erosion at the estuary mouth, and aggradation of the tidal bars. The second pattern represents variations in channel volume below $-5 \mathrm{~m}$.

(3) The $70 \%$ reduction of the Changjiang sediment load seems not having an impact on the NB morphology, while reclamation of the intertidal area along the NB is directly responsible for the reduction of the NB tidal prism. Enhanced flood-tidal currents have possibly carried sediments into the NB between 1958 and 2013 reducing the channel volume below $0 \mathrm{~m}$. Enhanced tidal asymmetry due to lower water depths has likely favored tidal pumping, one of the main processes responsible for silting.

(4) If the current rates of channel aggradation continue in the future, the NB will likely vanish in the 2060s. However, the restoration of the funnel shape of the estuary by recovering the mud flat area above sea level, the cutting of the southern, inner part of the estuary bend in the upper segment of the estuary, and the prevention of land reclamation may reduce the risk of siltation.

\section{Acknowledgements}

This study was supported by the National Science Foundation of China (41576087, 51479074) and New Century Excellent Talents in University of China (NCET-12-0182). We are also grateful to the editor and two anonymous reviewers for their constructive comments and suggestions that improved the article. 


\section{References:}

Aldridge, J.N., 1997. Hydrodynamic model predictions of tidal asymmetry and observed sediment transport paths in Morecambe Bay. Estuarine, Coastal and Shelf Science 44, 39-56.

Anthony, E.J., Brunier, G., Besset, M., Goichot, M., Dussouillez, P., Nguyen, V.L., 2015. Linking rapid erosion of the Mekong River delta to human activities. Scientific Reports, 5:14745; doi: 10.1038/srep14745.

Ayles, C.P., Lapointe, M.F., 1996. Downvalley gradients in flow patterns, sediment transport and channel morphology in a small macrotidal estuary: Dipper Harbour Creek, New Brunswick, Canada. Earth Surface Processes and Landforms 21, 829-842.

Bulletin of China River Sediment (BCRS), 2010. Press of Ministry of Water Resources of the People's Republic of China. http://www.cjh.com.cn/.

Canestrelli, A., Fagherazzi, S., Defina, A., Lanzoni, S., 2010. Tidal hydrodynamics and erosional power in the Fly river delta, Ppua New Guinea. Journal of Geophysical Research 115, F4033. http://doi: 10.1029/2009JF001355.

Canestrelli, A., Lanzoni, S., Fagherazzi, S., 2014. One-dimensional numerical modeling of the longterm morphodynamic evolution of a tidally-dominated estuary: the lower Fly river (Papua New Guinea). Sedimentary Geology 301, 107-119.

Capo, S., Sottolichio, A., Brenon, I., Castaing, P., Ferry, L., 2006. Morphology, hydrography and sediment dynamics in a mangrove estuary: the Konkoureetuary, Guinea. Marine Geology 230, 199-215.

Chen, J.Y., Yun, C.X., Xu, H.G., 1982. The model of development of the Yangtze Estuary during the last 2000 years. In: Kennedy, V.S.Z. (ed.) (ed) Estuarine comparisons. Academic Press, New York, pp 655-666.

Chen, S.L., Gu, G.C., Liu, Y.S., 2003. Formation conditions and initial site of tidal bore in the north branch of Yangtze River estuary. Journal of Hydraulic Engineering 11, 30-36 (in Chinese with English abstract).

Chen, J. Y., 2007. Research and practice of estuary and coast in China. Higher Education Press, Beijing, China.

Chen, Z.Y., Wang, Z.H., Finlayson, B., Chen, J., Yin, D.W., 2010. Implications of flow control by the Three Gorges Dam on sediment and channel dynamics of the middle Yangtze (Changjiang) River, China. Geology 38 (11), 1043-1046.

Cuvilliez, A., Deloffre, J., Lafite, R., Bessineton, C., 2009. Morphological responses of an estuarine intertidal mudflat to constructions since 1978 to 2005: the Seine estuary (France). Geomorphology 104, 165-174.

Dai, Z.J., Liu, J.T., Lei, Y.P., Zhang, X.L., 2008. Patterns of sediment transport pathways on a headland bay beach-Nanwan beach, South China: a case study. Journal of Coastal Research 26 (6), 1096-1103.

Dai, Z.J., Du, J.Z., Chu, A., Zhang, X.L., 2011. Sediment characteristics in the North Branch of the Yangtze estuary based on radioisotope tracers. Environmental Earth Science 62, 1629-1634.

Dai, Z.J., Liu, J.T., Fu, G., Xie, H.L., 2013. A thirteen-year record of bathymetric changes in the North Passage, Changjiang (Yangtze) estuary. Geomorphology 187, 101-107.

Dai, Z.J., Liu, J.T., Wei, W., Chen, J.Y., 2014. Detection of the Three Gorges Dam influence on the Changjiang (Yangtze River) submerged delta. Scientific Reports 4, 6600: doi: 10.1038/srep06600.

Dai, Z.J., Liu, J.T., Wei, W., 2015. Morphological evolution of the South Passage in the Changjiang (Yangtze River) estuary, China. Quaternary International 380-381, 314-326.

Davis, J.L., 1964. A morphogenic approach to world shorelines. Z. Gemorphologie 8, 127-142. 
de Swart, H.E., Zimmerman, J.T.F., 2009. Morphodynamics of tidal inlet systems. Annual Review of Fluid Mechanics 41, 203-229.

Emery, W.J., Thomson, R.E., 2001. Data Analysis Methods in Physical Oceanography, second ed. Elsevier, Amsterdam, p. 638.

Fagherazzi, S., Carniello, L., D’Alpaos, L., Defina, A., 2006. Critical bifurcation of shallow microtial landforms in tidal flats and salt marshes. PNAS 103 (22), 8337-8341.

Feng, L.X., Li, J.F., Dai, Z.J., Yan, H., Zhao, J.C., 2009. Analysis of the river channel stability and the characteristics of suspended sediment and water in the North Branch of the Changjiang river estuary in recent years. Journal of Marine Sciences 27 (3), 40-47 (in Chinese with English abstract).

Friedrichs, C.T., Aubrey, D.G. 1988. Non-linear tidal distortion in shallow well-mixed estuaries: a synthesis. Estuarine, Coastal and Shelf Science, 27(5), 521-545.

Heap, A.D., Bryce, S., Ryan, D.A., 2004. Facies evolution of Holocene estuaries and deltas: a largesample statistical study from Australia. Seimentary Geology 168, 1-17.

Ikeda, S., Parker, G., Sawai, K., 1981. Bend theory of river meanders: Part 1. Linear development. Journal of Fluid Mechanics 112, 363-377.

Jaffe, B.E., Smith, R.E., Foxgrover, A.C., 2007. Anthropogenic influence on sedimentation and intertidal mudflat change in San Pablo Bay, California: 1856-1983. Estuarine, Coastal and Shelf Science 73, 175-187.

Kim, T.I., Choi, B.H., Lee, S.W., 2006. Hydrodynamics and sedimentation induced by large-scale coastal developments in the Keum river estuary, Korea. Estuarine, Coastal and Shelf Science 68, 515-528.

Lanzoni, S., Seminara, G., 2002. Long-term evolution and morphodynamic equilibrium of tidal $\begin{array}{llllll}\text { channels.Journal of } & \text { Geophysical Research } 107 & \text { (C7), } & 3001 .\end{array}$ http://dx.doi.org/10.1029/2000JC000468.

Lane, A., 2004. Bathymetric evolution of the Mersey Estuary, UK, 106-1997: causes and effects. Estuarine, Coastal and Shelf Science 59, 249-263.

Liu, J.T., Lin, H.L., 2004. Sediment dynamics in a submarine canyon: a case of river-sea interaction. Marine Geology 207, 55-81.

Liu, J.P., Xu, K.H., Li, A.C., Milliman, J.D., Velozzi, D.M., Xiao, S.B., Yang Z.S., 2007. Flux and Fate of Yangtze River Sediment Delivered to the East China Sea, Geomorphology, 85 (3-4), 208224. 10.1016/j.geomorph.2006.03.023.

Mitchell, S.B., Lawler, D.M., West, J.R., Couperthwaite, J.S., 2003. Use of continuous turbidity sensor in the prediction of fine sediment transport in the turbidity maximum of the Trent Estuary, UK. Estuarine, Coastal and Shelf Science 58, 645-652.

Morris, 2013. Geomorphological analogues for large estuarine engineering projects: a case study of barrages, causeways and tidal energy projects. Ocean and Coastal Management 9, 52-61.

Perillo, G.M.E., 1995. Geomorphology and Sedimentology of Estuaries. Elsevier, Amsterdam.

Pittaluga, M.B., Tambroni, N., Canestrelli, A., Slingerland, R., Lanzoni, S., Seminara, 2014. Where river and tide meet: the morphodynamic equilibrium of alluvial estuaries. Journal of Geophysical Research-Earth 75, 10.1002/2014JF003233.

Postma, H., 1961. Transport and accumulation of suspended matter in the Dutch Wadden Sea. Netherlands Journal of Sea Research 1, 148-190.

U.S. Environmental Protection Agency (USEPA), 1993. Volunteer estuary monitoring: a methods manual. EPA 842-b-93-004. Washington, DC: USEPA Office of water. p. 176.

Roy, P.S., Williams, R.J., Jones, A.R., Yassini, I., Gibbs, P.J., Coates, B., West, R.J., Scanes, P.R., 
Hudson, J.P., Nichol, S.L., 2001. Structure and function of south-east Australian estuaries. Estuarine, Coastal and Shelf Science 53, 351-384.

Seminara, G., Lanzoni, S., Tambroni, N., Toffolon, M., 2010. How long are tidal channels? Journal of Fluid Mechanics 643, 479-494.

Simmons, H.B., 1955. Some effects of upland discharge on estuarine hydraulics, 1955. Separate Paper No. 792. In: Proceedings ASCE, vol. 81. ASCE Press, Reston, VA.

Spearman, J.R., Dearnale, M.P., Dennis, J.M., 1998. A simulation of estuary response to training wall construction using a regime approach. Coastal Engineering 33, 71-89.

Speer, P.E., Aubrey, D.G., Friedrichs, C., 1991. Non-linear tidal propagation in shallow inlet/estuarine systems, Part 2, Theory. Estuarine, Coastal and Shelf Science 21, 206-240.

Syvitski, J.P.M., Vörösmarty, C.J., Kettner, A.J., Green, P., 2005. Impact of humans on flux of terrestrial sediment to the global coastal ocean. Science 308 (15), 376-380.

Syvitski, J.P.M., Vörösmarty, C.J., Kettner, A.J., Green, P., 2009. Sinking deltas due to human activities. Nature Geoscience 2, 681-689.

Tambroni, N., Pittaluga, M.B., Seminara, G., 2005. Laboratory observations of the morphodynamic evolution of tidal channels and tidal inlets. Journal of Geophysical Research 110, F04009. http://dx.doi.org/10.1029/2004JF000243.

Thomas, C.G., Spearman, J.R., Turnbull, M.J., 2002. Historical morphological change in the Mersey estuary. Continental Shelf Research 22, 1775-1794.

Todeschini, I., Toffolon, M., Tubino, M., 2008. Long-term morphogical evolution of funnelshape tide-dominated estuaries. Journal of Geophysical Research 113, C05005. Http://dddx.doi.org/10.1029/2007JC004094.

Uncles, R.J., Stephens, J.A., 1997. Dynamics of turbidity in the Tweed Estuary. Estuarine, Coastal and Shelf Science 45, 745-758.

Van der Wal, D., Pye, K., Neal, A., 2002. Long-term morphological change in the Ribble Estuary, northwest England. Marine Geology 189, 249-266.

van Der Wal, D., Pye, K., 2004. Patterns, rates and possible causes of saltmarsh erosion in the Greater Thames area (UK). Geomorphology 61, 373-391.

van der Wegen, Jaffe, B.E., Roelvink, J.A., 2010. Process-based, morphodynamic hindcast of decadal deposition patterns in San Pablo Bay, California, 1856-1887. Journal of Geophysical Research 116, F02008, doi: 10.1029/2009JF001614.

Wallace, J.W., Dickinson, 1972. Empirical orthogonal representation of time series in the frequency domain, part 1: theoretical consideration. Journal of Applied Meteorology 11, 887-892.

Wang, Y.H., Dong, P., Oguchi, T., Chen, S.L., Shen, H.T., 2013. Long-term (1842-2006) morphological change and equilibrium stateof the Changjiang (Yangtze) Estuary, China. Continental Shelf Research 56, 71-81.

Wolanski, E., Spagnol, S., 2000. Environmental degradation by mud in tropical estuaries. Regional Environmental Change 1, 152-162.Wolanski, E., 2006. The evolution time scale of macro-tidal estuaries: examples from the Pacific Rim. Estuarine, Coastal and Shelf Science 66, 544-549.

Wolanski, E., Moore, K., Spagnol, S., D'adamo, N. and Pattiaratchi, C., 2001. Rapid, humaninduced siltation of the macro-tidal Ord River Estuary, Western Australia. Estuarine, Coastal and Shelf Science, 53(5), pp.717-732.

Woodroffe, C.D., 2003. Coasts, Form, Process and Evoltion. Cambridge University Press, p. 623.

Wright, L.D., Coleman, J.M., 1973. Variations in morphology of major river deltas as a function of ocean waves and river discharge regimes. American Association of Petroleum Geology Bulletin 57 177-205. 
Yang, S.L., Zhang, J., Xu, X.J., 2007. Influence of the Three Gorges dam on downstream delivery of sediment and its environmental implications, Yangtze River. Geophysical Research Letters 34, L10401, doi: 10.1029/2007GL029472.

Yun, C.X., 2004. Evolutionary Rules of the Changjiang Estuary in Recent Decades. China Ocean Press, Beijing (ISBN: 750276219).

Zhou, K.S., Meng, Y., Liu, C.Z., Hong, X.Q., 2005. Characteristics of aggradation and granularity for the north branch of Changjiang River estuary and its environmental implication. Marine Geology Letters 21(11), 1-7 (in Chinese with English abstract).

Zhou, K.S., Meng, Y., Liu, C.Z., Hong, X.Q., 2007. Analysis of the source of tidal sandy sediments in the north branch of Changjiang river estuary. Journal of Hainan Normal University (Natural Science) 20 (3), 277-282 (in Chinese with English abstract). 


\section{Captions:}

Fig. 1 Research area and location of survey stations. a: location of the Yangtze watershed in China; b: The four branches of the Changjiang estuary; c: the North Branch and associated hydrological stations

Fig. 2 Water depths below $0 \mathrm{~m}$ along the North Branch in different years

Fig. 3 Yearly variations in water depth and channel volume (a. mean water depth, b. channel volume below $0 \mathrm{~m}$, c. channel volume below $-5 \mathrm{~m}$ )

Fig. 4 Bathymetric changes along the North Branch axis from 1958 to 2013. The axis is displayed in Fig. 1c.

Fig. 5 Accretion and erosion in different time intervals from 1958 to 2013 computed from the water depths reported in Fig. 2

Fig. 6. Erosion/accretion pattern in the North Branch identified by EOF analysis. a: contoured eigenvectors of the first mode, $b$ : the first mode eigenweightings, $c$ : contoured eigenvectors of second mode, and d: the second mode eigenweightings.

Fig. 7 Relations between eigenweigting and channel volumes (a: plots of channel volumes below $0 \mathrm{~m}$ vs. the eigenweigting of the first mode; $b$ : plots of channel volumes below $-5 \mathrm{~m}$ vs. the eigenweigting of the second mode)

Fig. 8 Yearly water and sediment load at Datong station

Fig. 9 Spatial variations in flood/ebb current directions in the North Branch and South Branch (Synchronous survey date: 22, Sept. 2002)

Fig. 10 Ebb flow partition of the North Branch between 1958 and 2011

Fig. 11 Bend angle in the upper segment between 1958 and2013

Fig. 12 Relations between bend angle and a. mean water depth, b. yearly channel volume below $0 \mathrm{~m}$

Fig. 13 Land reclamation in the North Branch from 1958 to 2013.

Fig. 14 Flow dominance coefficient at two gauge stations in different years. 

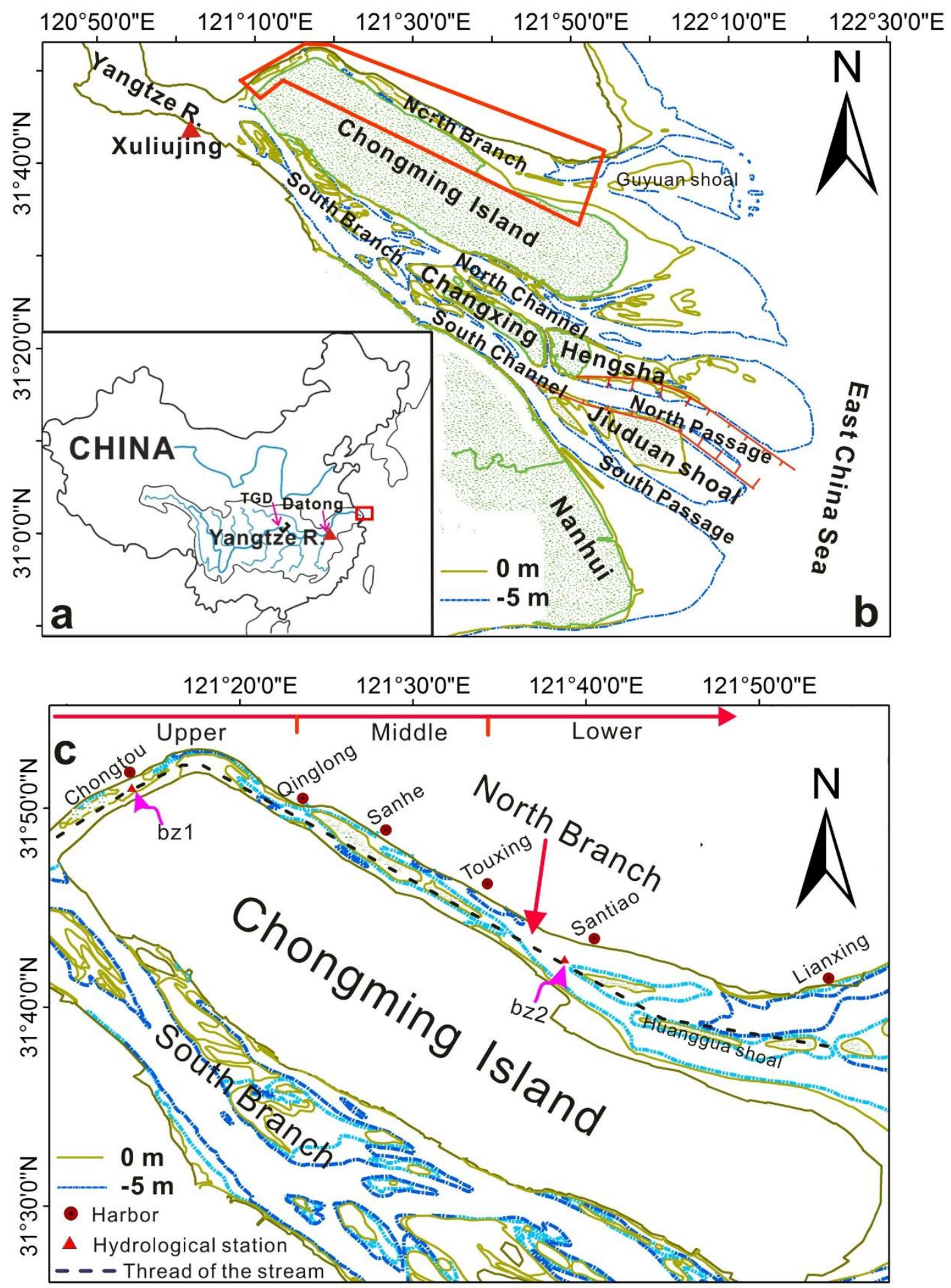


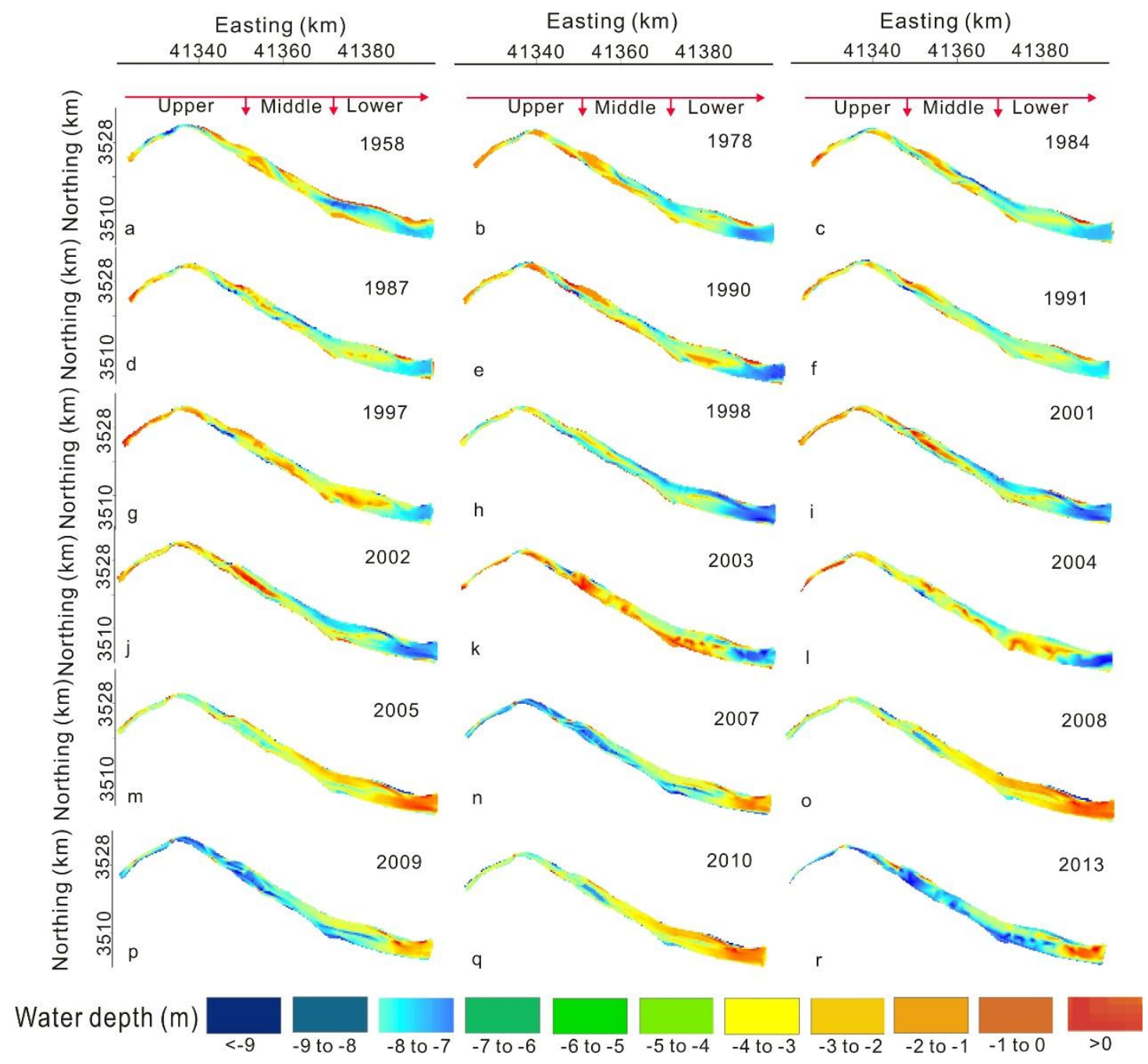



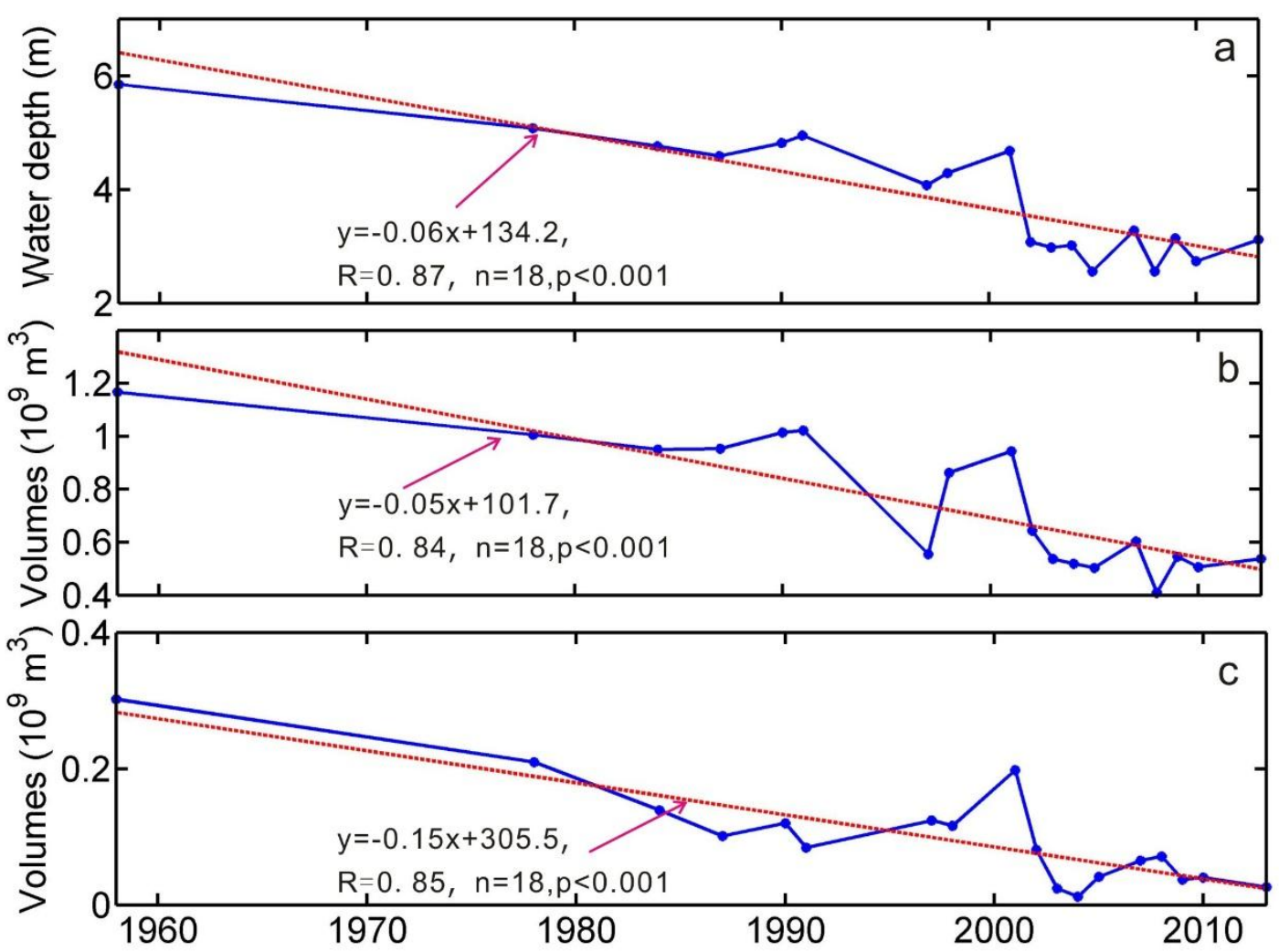

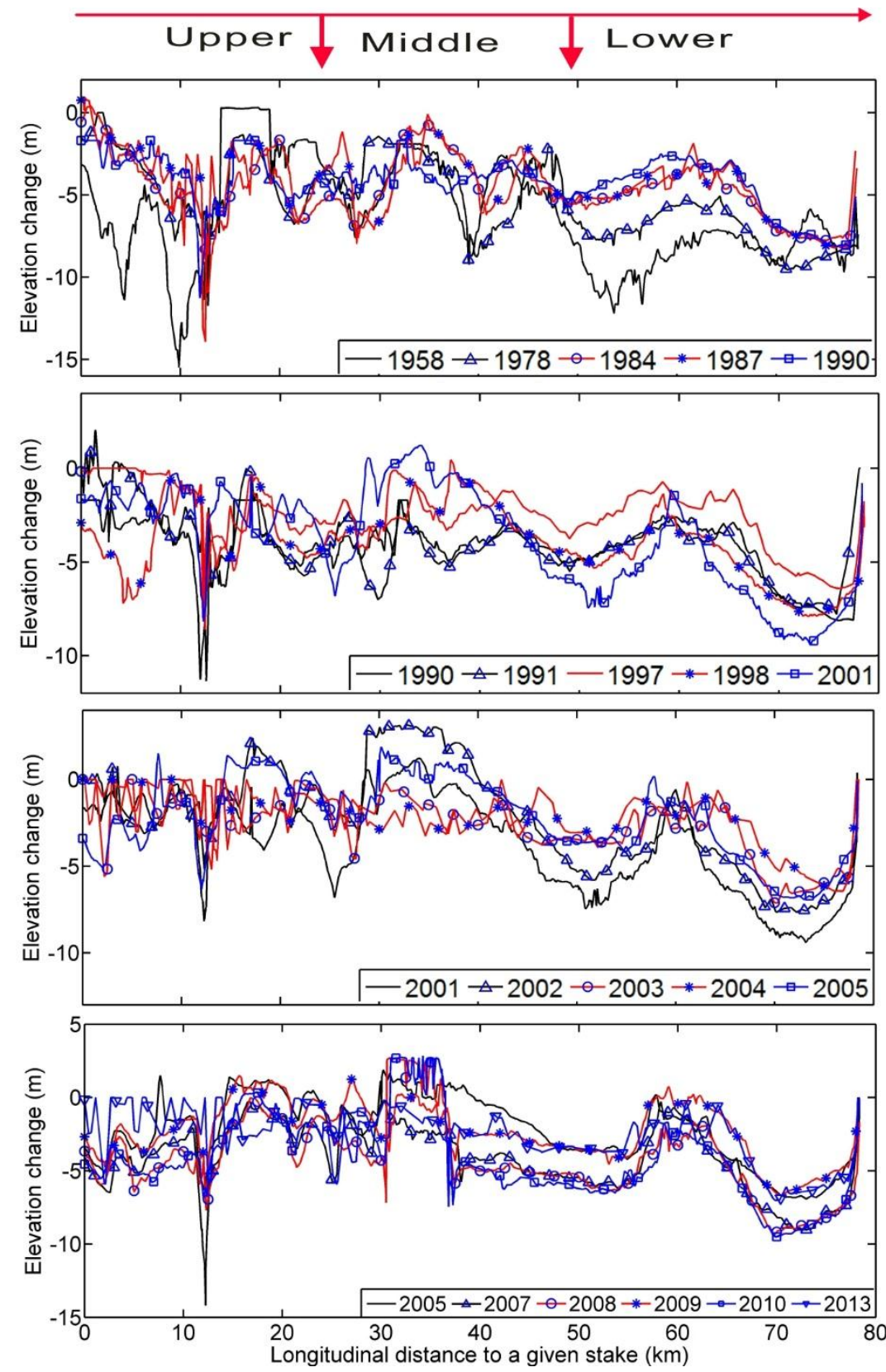


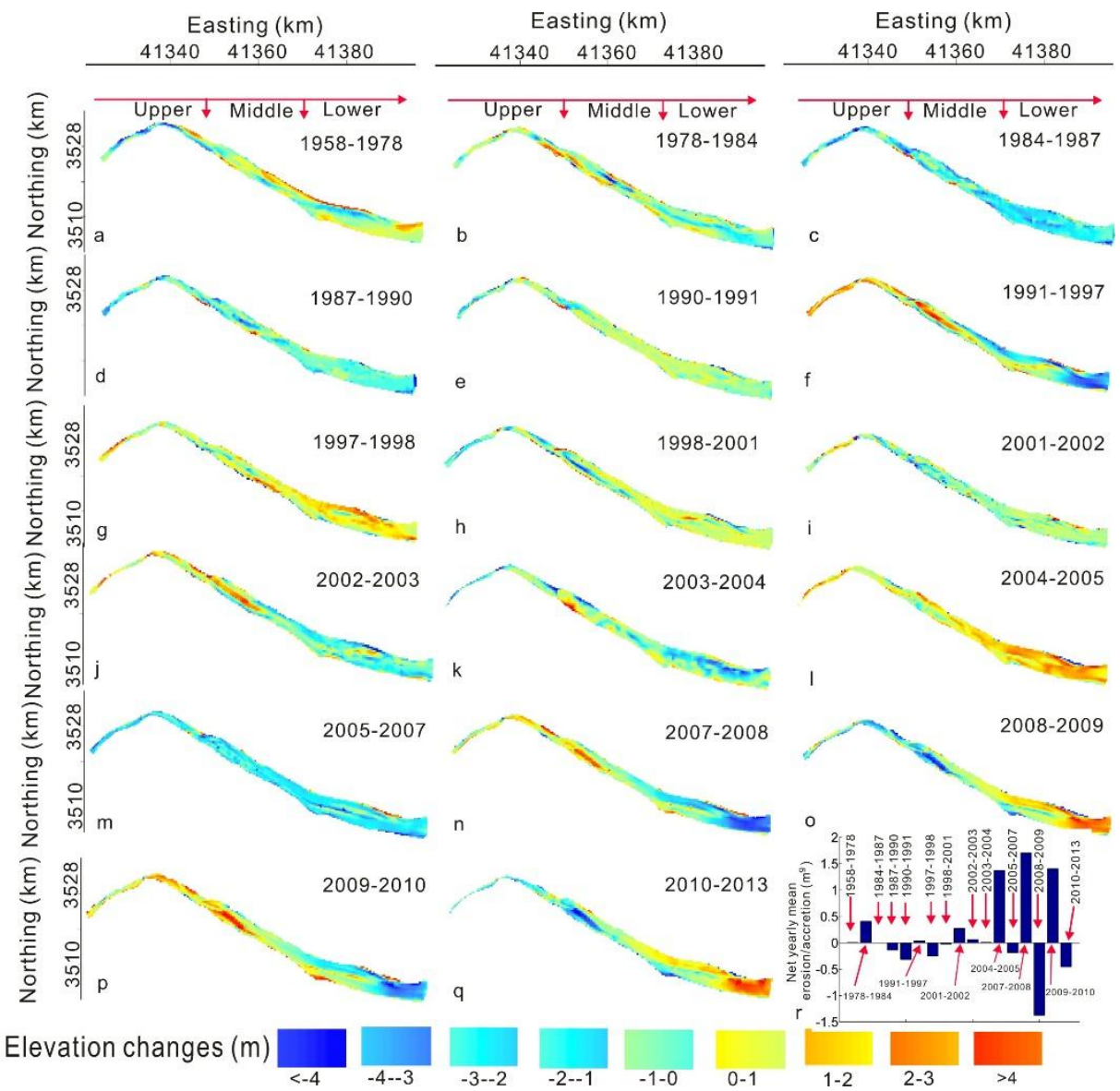



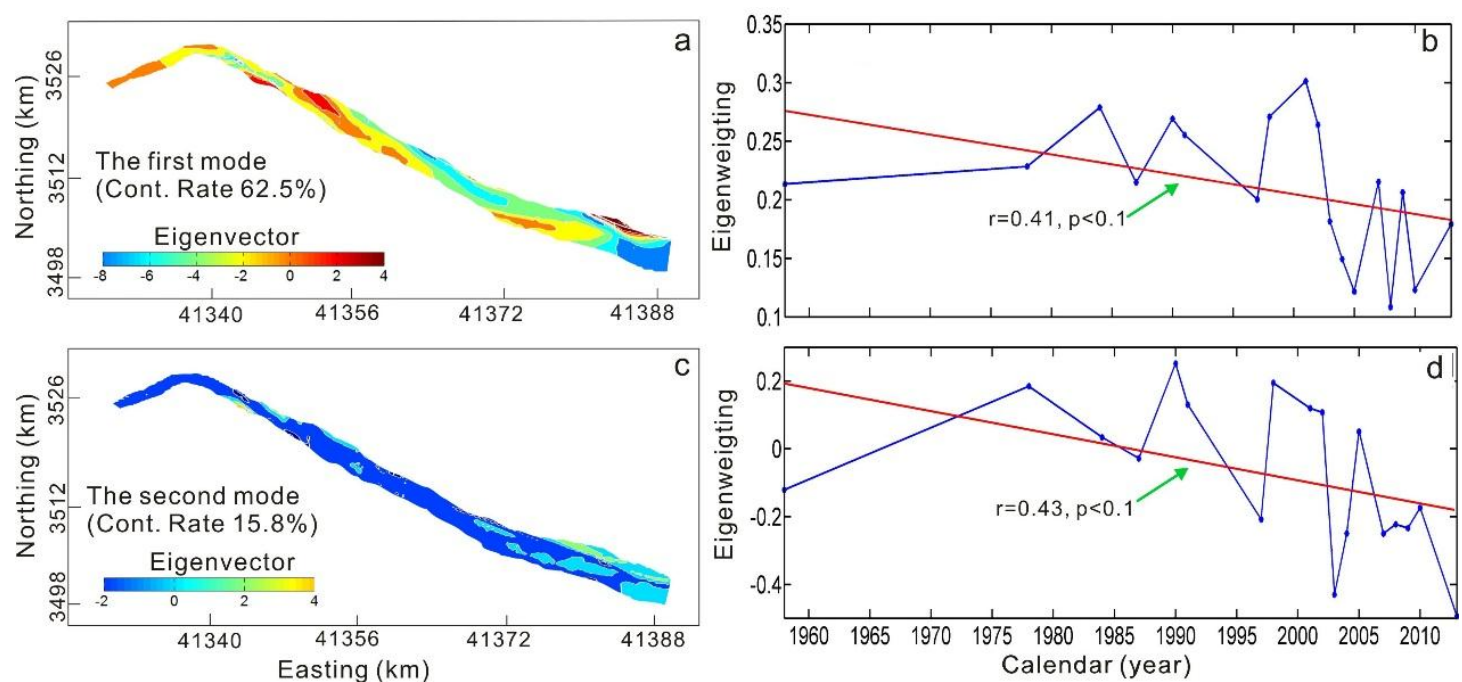


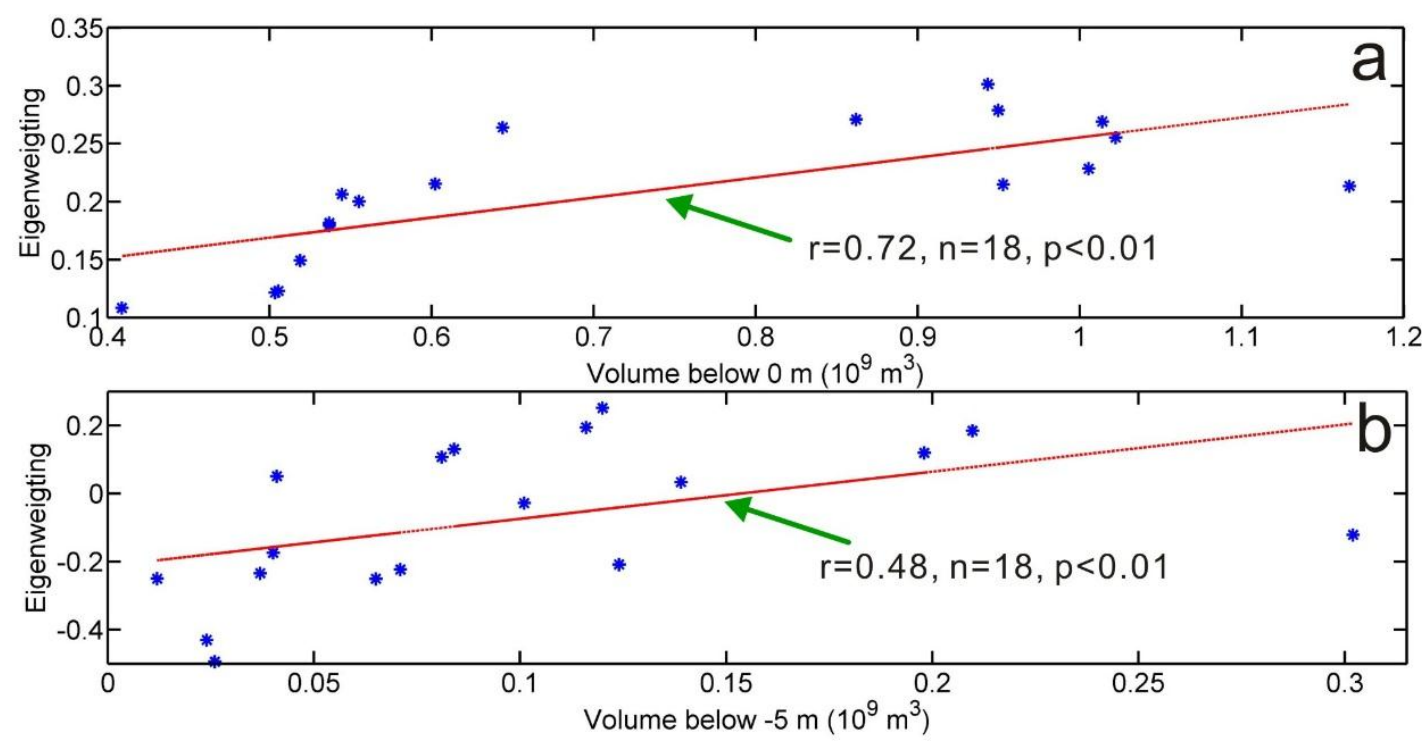



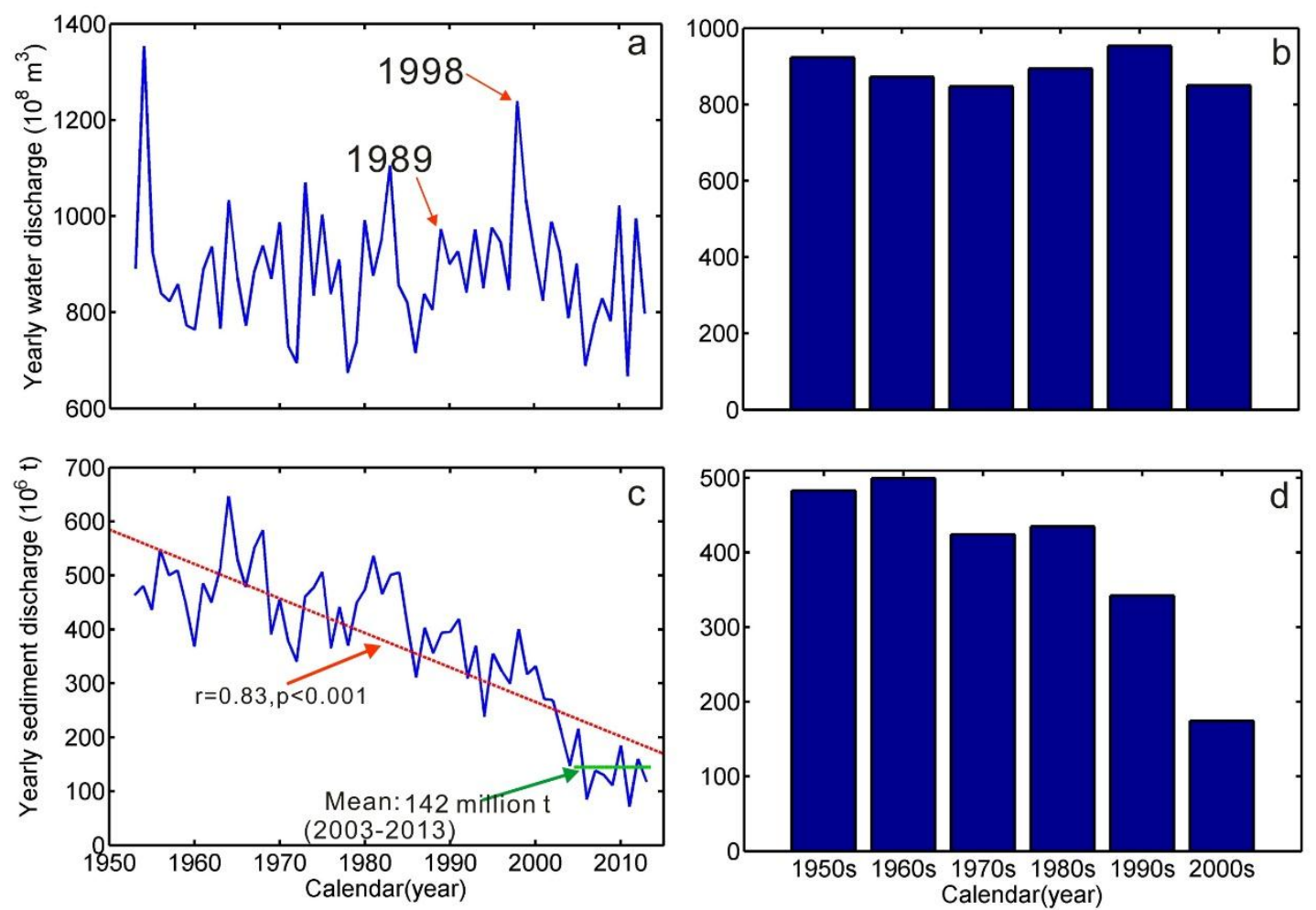


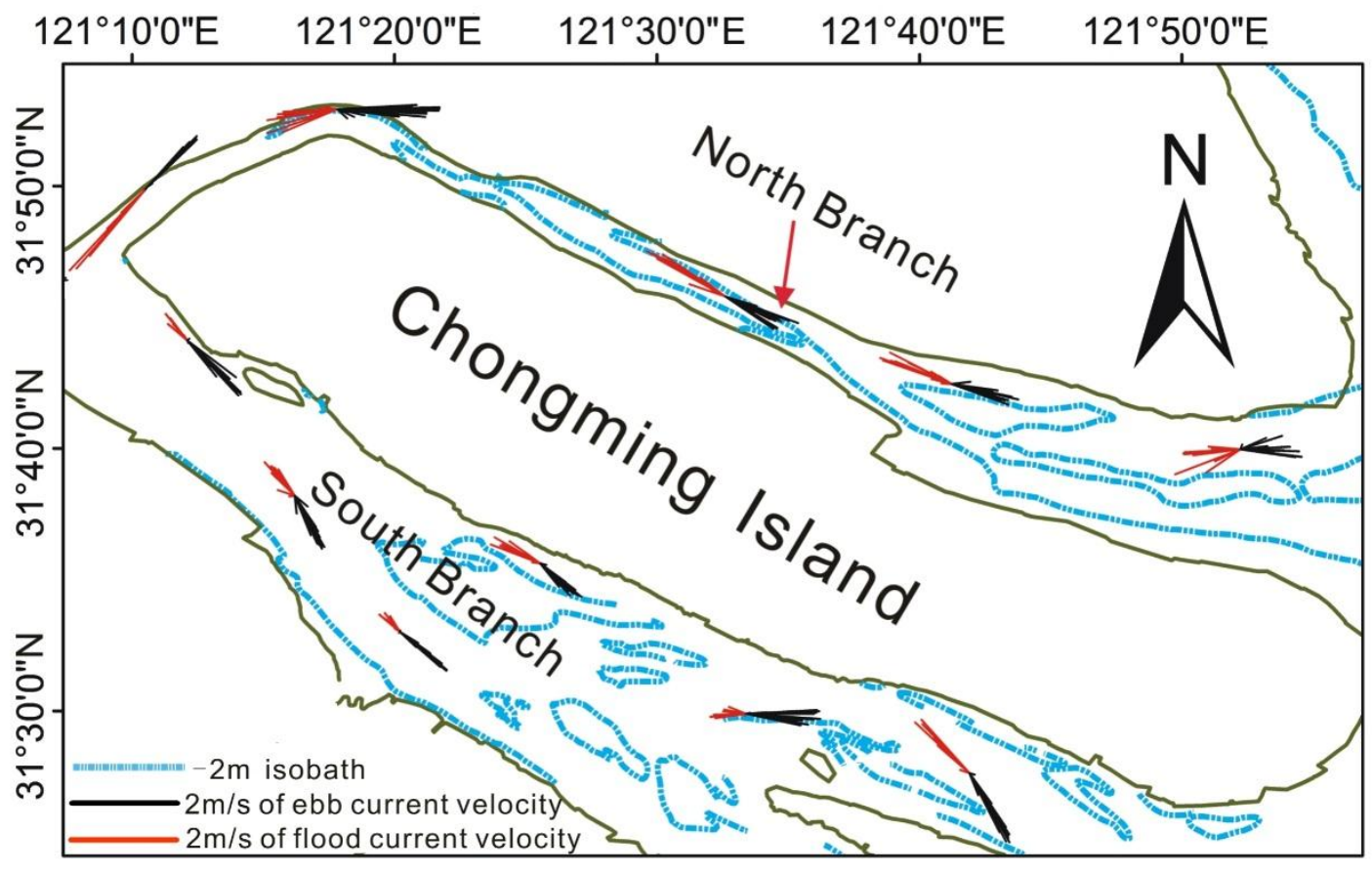




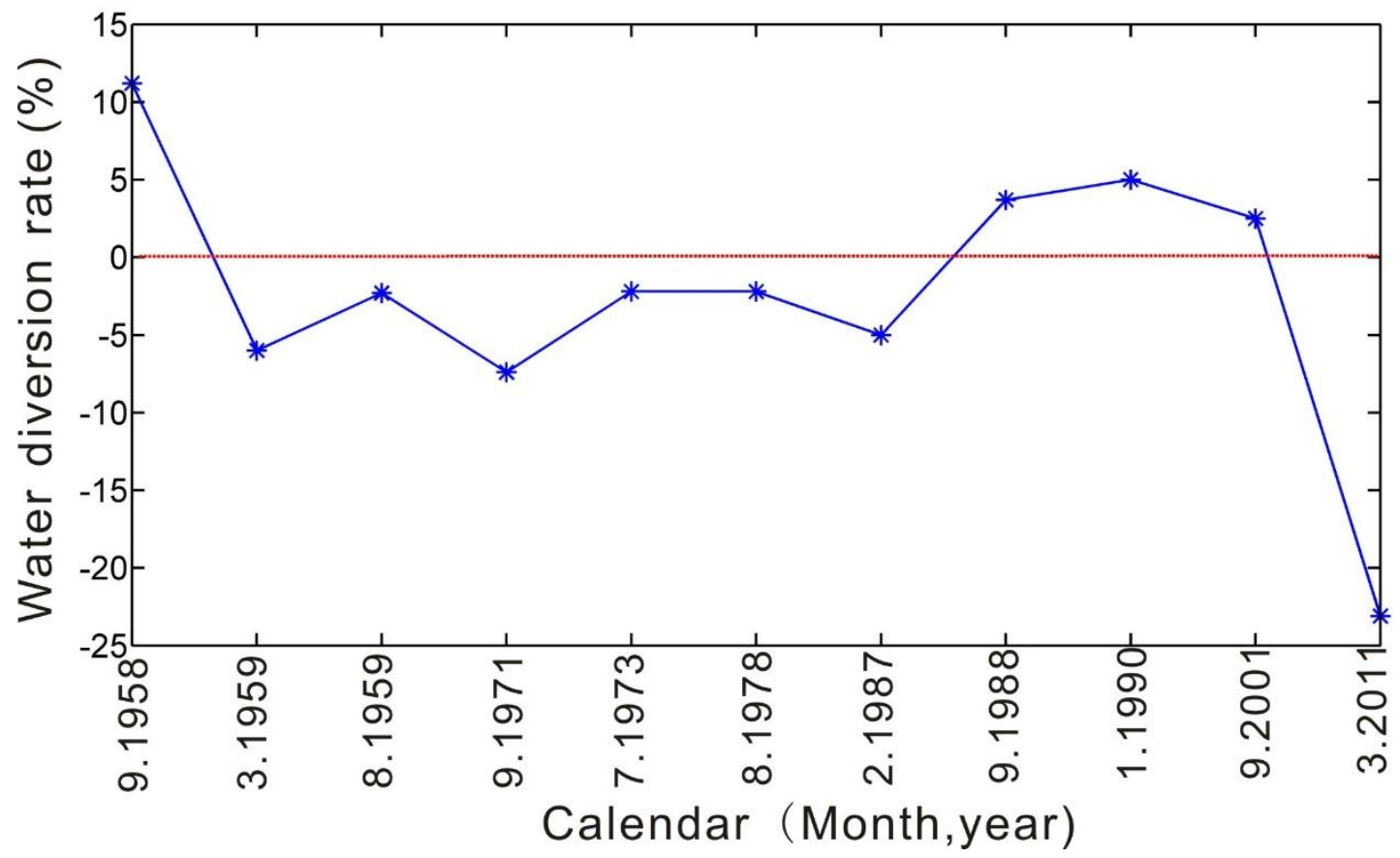




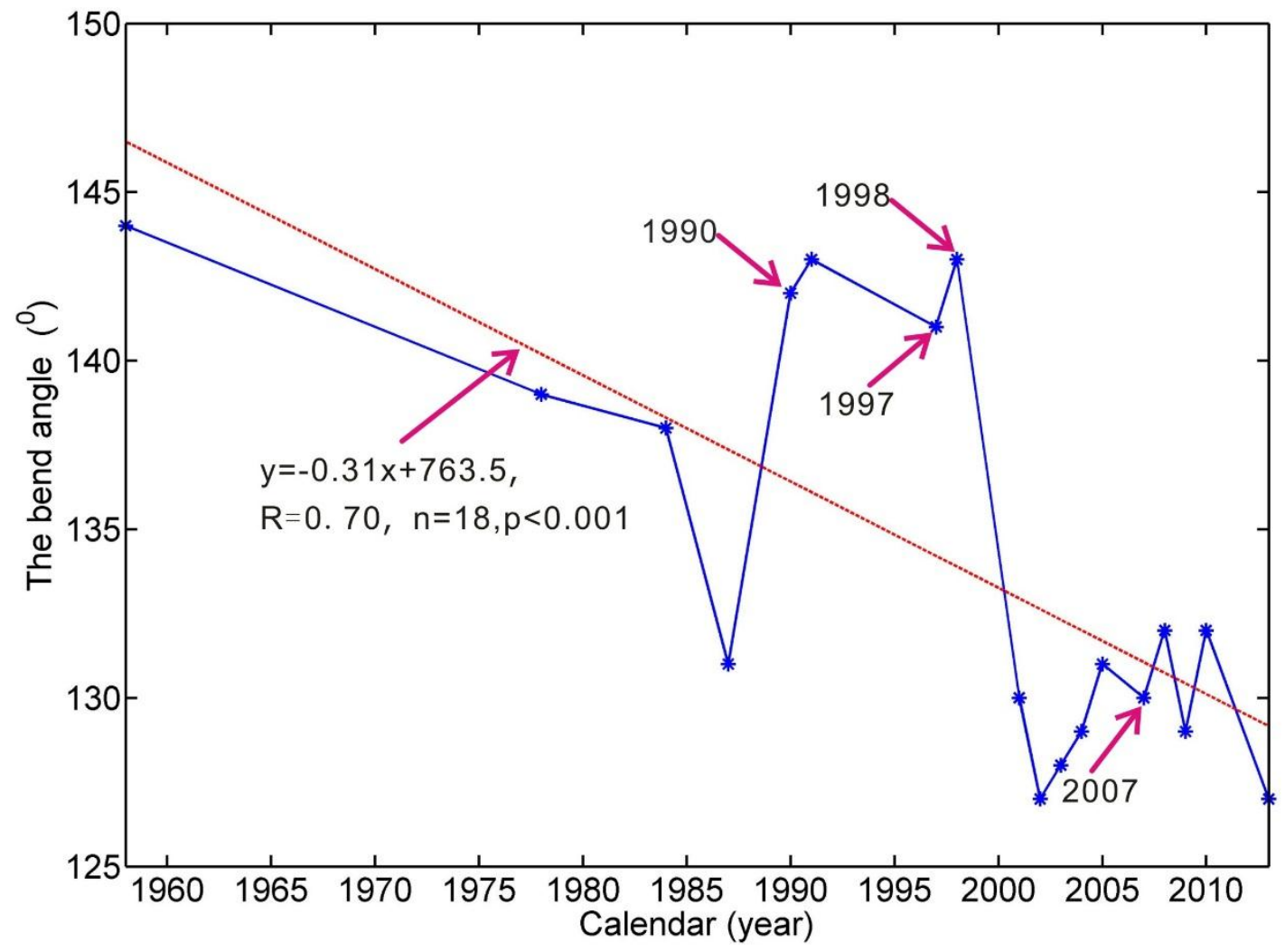




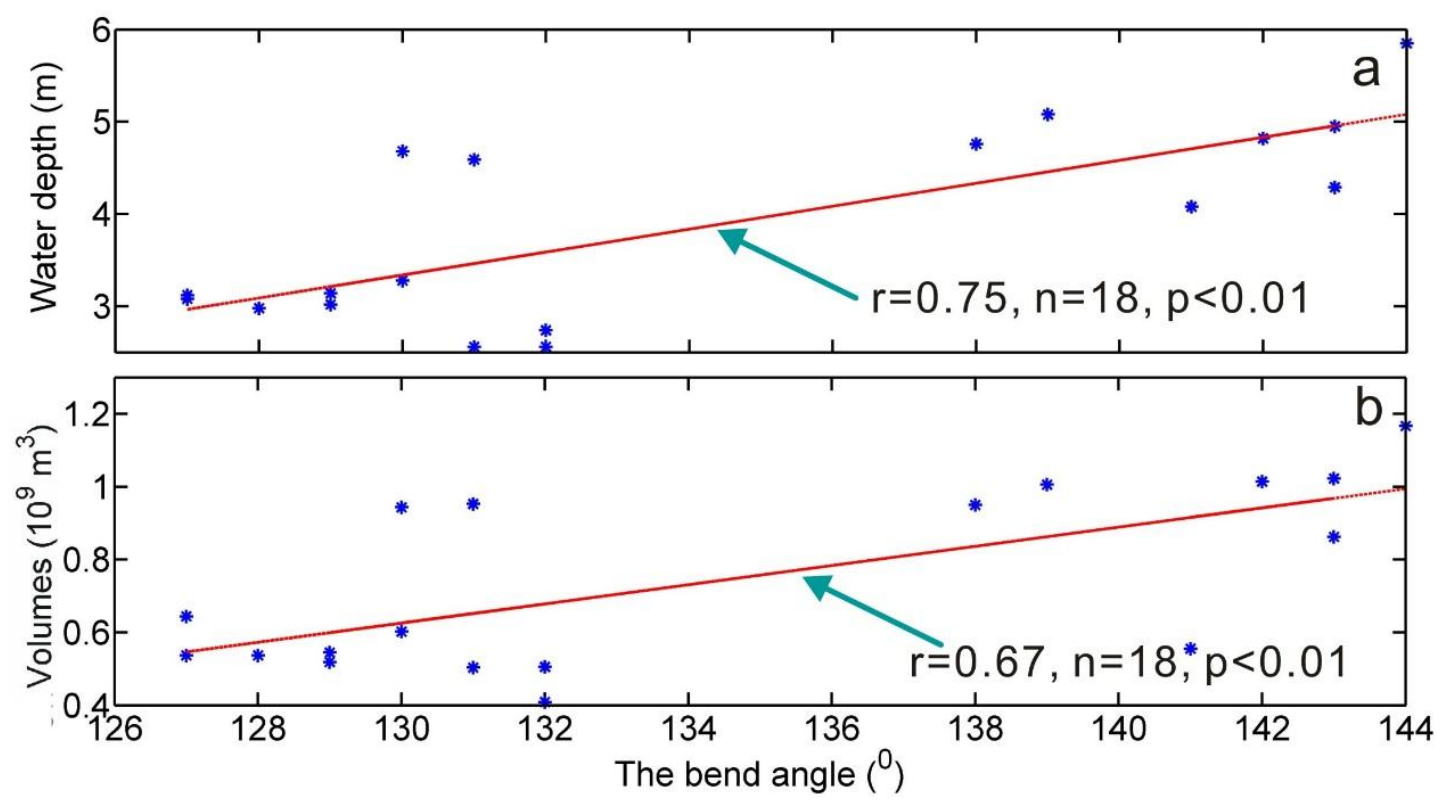




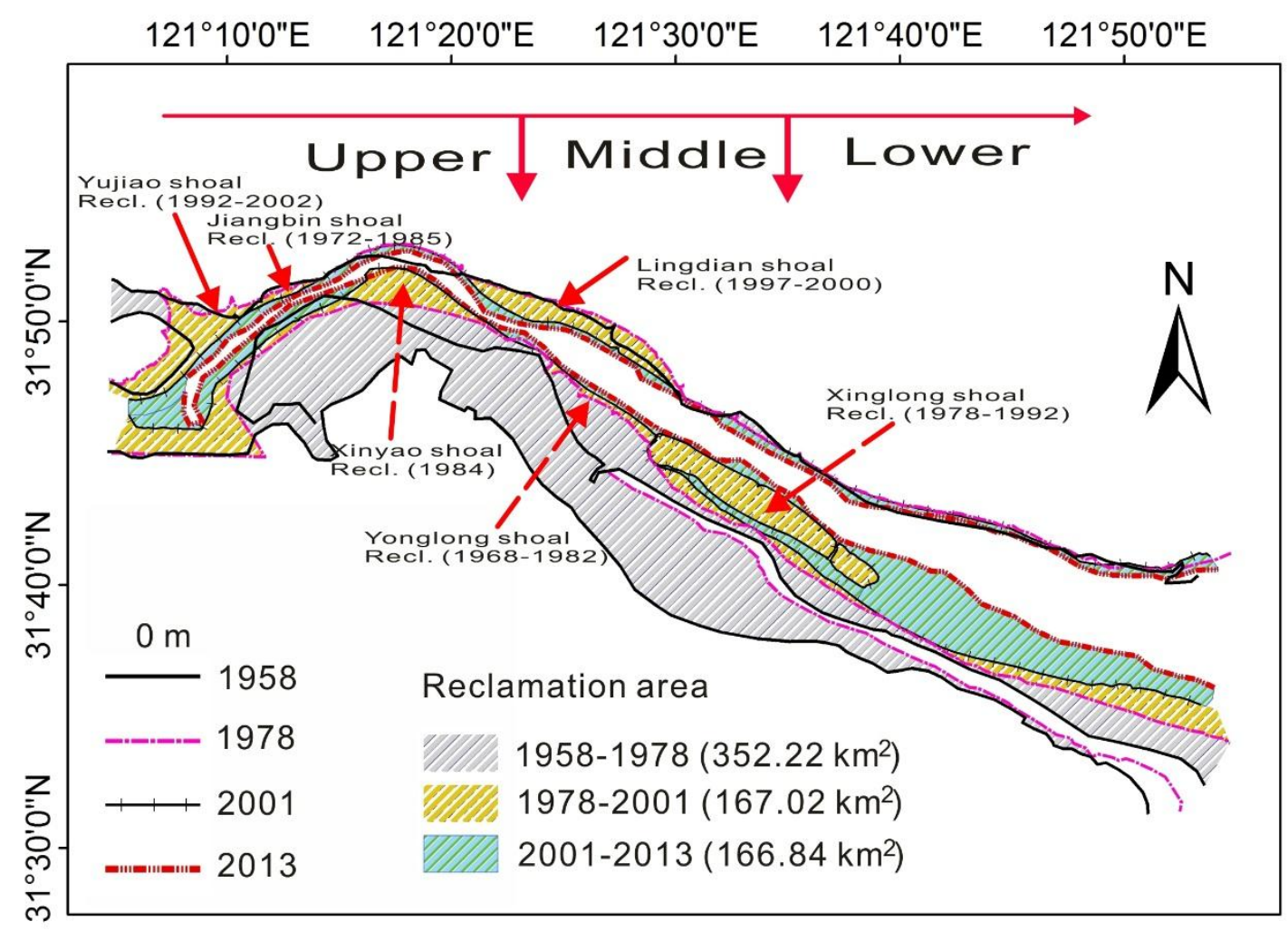




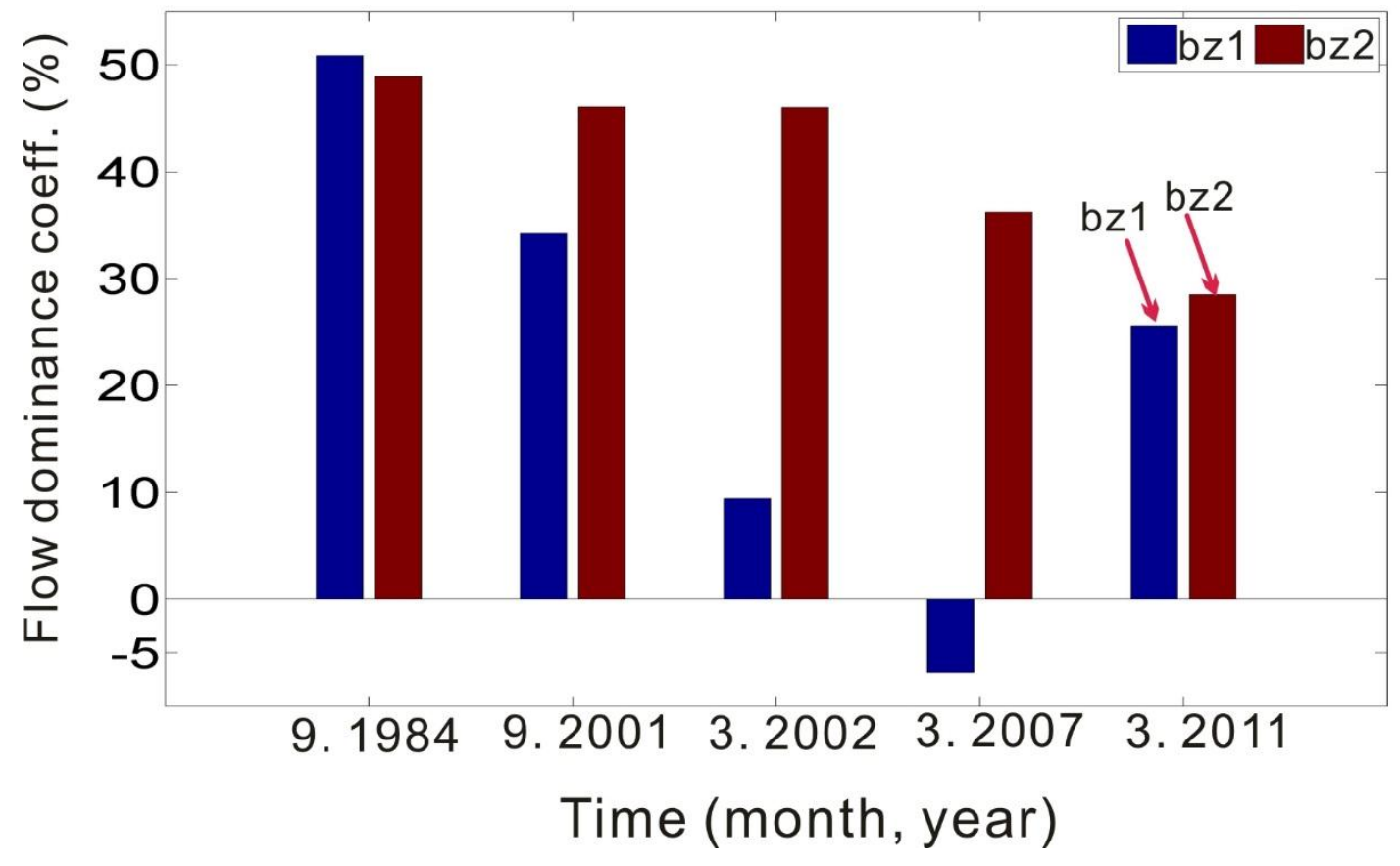


Table 1 Details about the bathymetric charts collected in the North Branch, Changjiang estuary

\begin{tabular}{llll}
\hline Surveyed date & Chart title & Scale & Data sources \\
\hline $\begin{array}{l}1958,1978,1984,1991,1998,2001, \\
2002,2005,2007,2008,2009,2010\end{array}$ & Beizhi Fairway & $1: 50,000$ & MSBSMCR $^{\mathrm{a}}$ \\
\hline $1987,1990,2003,2004,2013$ & $\begin{array}{l}\text { Northern Part of Changjiang } \\
\text { estuary }\end{array}$ & $1: 120,000$ & NGDCNH $^{\mathrm{b}}$ \\
\hline 1997 & $\begin{array}{l}\text { Changjiang Estuary and } \\
\text { adjacent area }\end{array}$ & & \\
\hline
\end{tabular}

a. MSBSMCR: Maritime Survey Bureau of Shanghai, Ministry of Communications of China.

b. NGDCNH: the Navigation Guarantee Department of the Chinese Navy Headquartes

c. HBCE: Hydrological Bureau of the Changjiang Estuary 

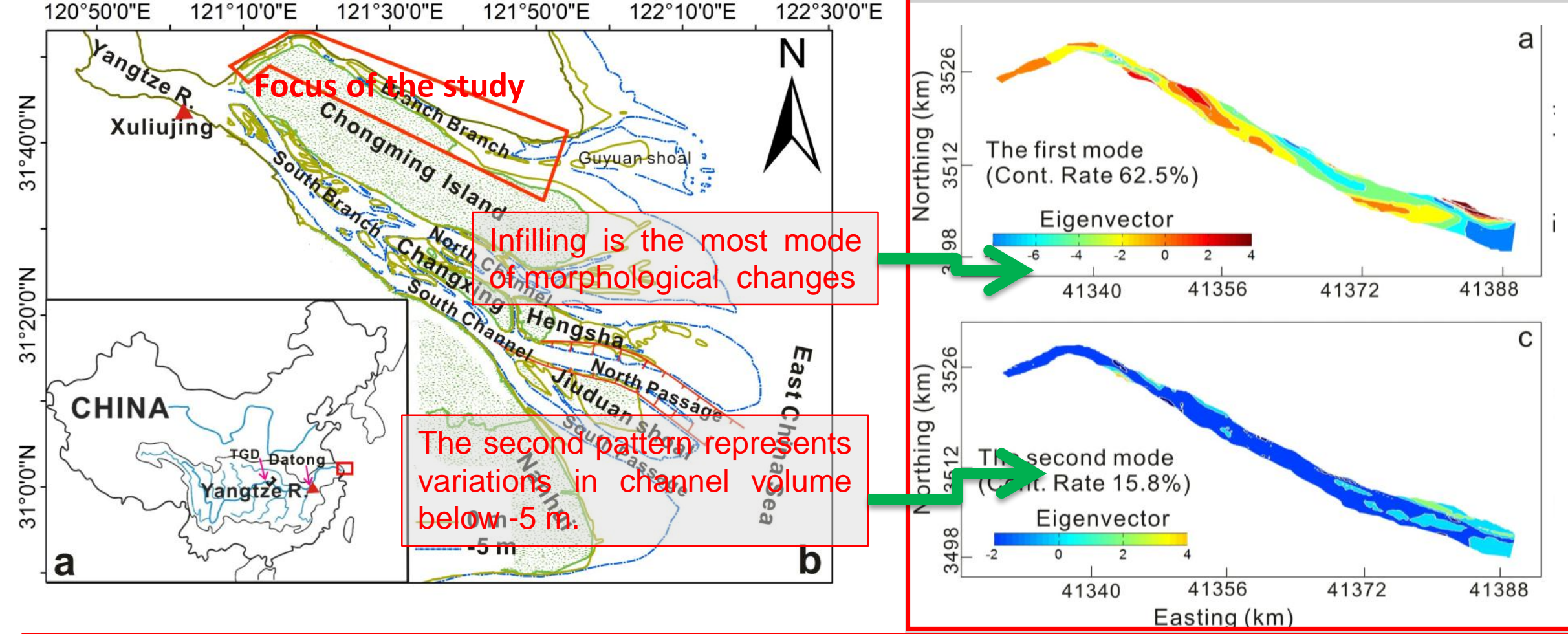

\section{Enhanced flood-tide currents have possibly carried sediments into the NB reducing the channel volume.}

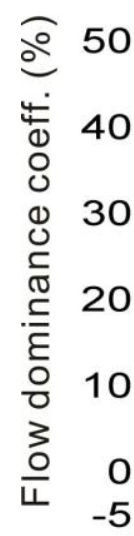

bz1 $\square z 2$

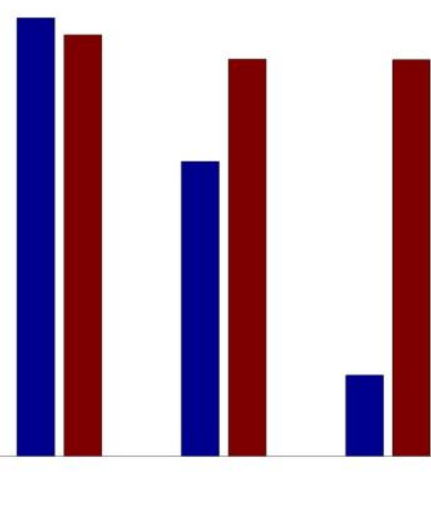

9. 1984
9. 2001 3. 2002

3. 2007

3. 2011
Reclamation of the intertidal area along the NB is directly responsible for the reduction of

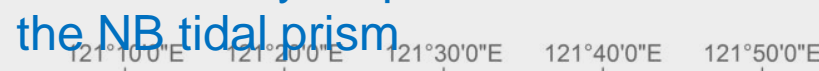

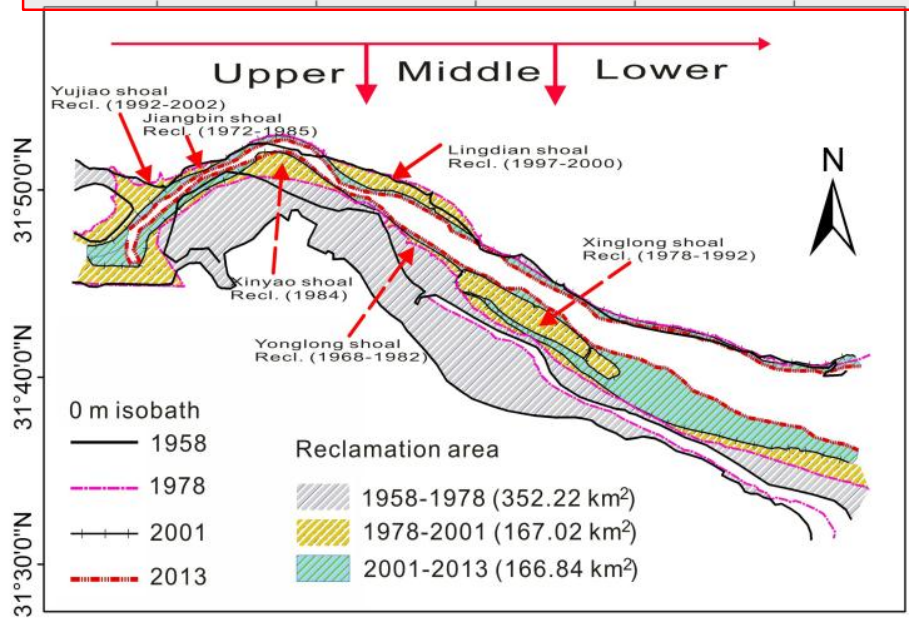

